University of Redlands

\title{
Visualizing and Analyzing a Neighborhood using the combination of GIS, Geodesign, New Urbanism
}

A Major Individual Project submitted in partial satisfaction of the requirements

for the degree of Master of Science in Geographic Information Systems

$$
\text { by }
$$

Abdullah Shubayli

Nader Afzalan, Ph.D., Committee Chair

Douglas Flewelling, Ph.D.

December 2016 
Visualizing and Analyzing a Neighborhood using the combination of GIS, Geodesign, New Urbanism

Copyright (C) 2016

by

Abdullah Shubayli 
The report of Abdullah Shubayli is approved.

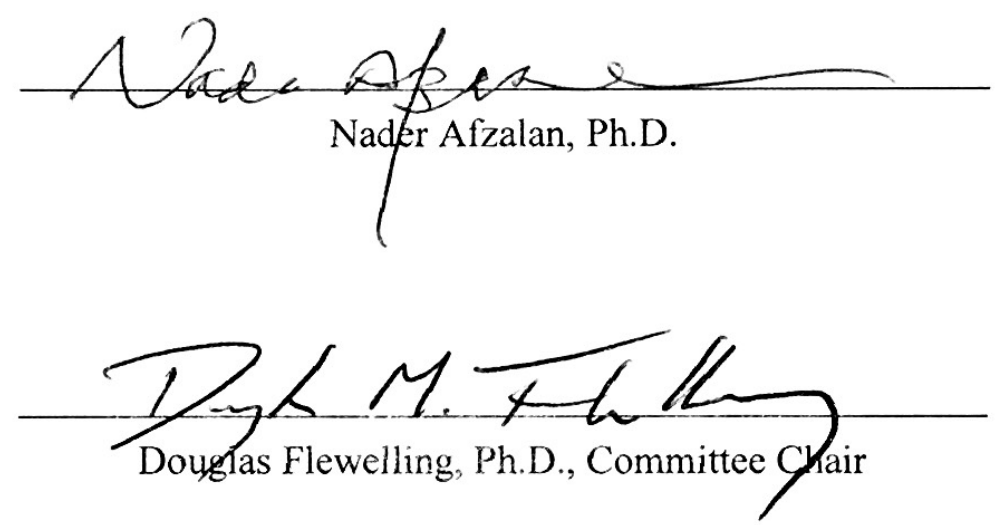

December 2016 



\section{Acknowledgements}

First and above all, I thank Allah for everything he has given me in this life and for providing me this opportunity and granting me the capability to proceed successfully. Also, would like to thank my family for supporting me spiritually throughout my life. I also would like to thank the MS GIS faculty members for guiding me throughout this program. A special thanks to Dr. Nader Afzalan for spending the time to advise and help me with this project. Lastly, I would like to thank my Cohort 27.5 and Cohort 27 for supporting and helping me throughout this master's program. I spent these days with the best supportive group of people. Again, thank you so much. 



\begin{abstract}
Visualizing and Analyzing a Neighborhood using the combination of GIS, Geodesign, New Urbanism

by

Abdullah Shubayli

Providing healthy and lively communities is becoming an increasingly important topic in Saudi Arabia. The Taif municipality and Al-Masaar Company wanted to obtain an actual simulation of a specific neighborhood of the city, and analyze its services' accessibility in order to evaluate the current urban design and to develop the proposed development. ArcGIS Pro and ArcGIS for Desktop were used to provide a three-dimensional model of the study area and to calculate and determine the service area for each facility. Therefore, geodesing technology and New Urbanism principles were incorporated into the project to design optimal scenarios for the study area. The project's outputs help provide a fuller understanding of complex urban planning regulations, and a better visualization for the current condition of the existed plan and the future development.
\end{abstract}





\section{Table of Contents}

Chapter 1 - Introduction 1

1.1 Client 2

$\begin{array}{lll}1.2 & \text { Problem Statement } & 3\end{array}$

$\begin{array}{lll}1.3 & \text { Proposed Solution } & 3\end{array}$

1.3.1 Goals and Objectives $\quad 4$

$\begin{array}{lll}\text { 1.3.2 Scope } & 4\end{array}$

$\begin{array}{lll}\text { 1.3.3 Methods } & 4\end{array}$

$\begin{array}{lll}1.4 & \text { Audience } & 5\end{array}$

1.5 Overview of the Rest of this Report 5

Chapter 2 - Background and Literature Review 7

$\begin{array}{lll}2.1 & \text { 3D GIS Modeling } & 7\end{array}$

$\begin{array}{llr}2.2 & \text { ArcGIS Network Analyst Extension } & 8\end{array}$

$2.3 \quad$ Geodesign Technology 9

$\begin{array}{lll}2.4 & \text { New Urbanism Principles } & 11\end{array}$

$\begin{array}{lll}2.5 & \text { Summary } & 14\end{array}$

Chapter 3 - Systems Analysis and Design 15

$\begin{array}{lll}3.1 & \text { Problem Statement } & 15\end{array}$

$\begin{array}{lll}3.2 & \text { Requirements Analysis } & 15\end{array}$

$\begin{array}{lll}3.3 & \text { System Design } & 17\end{array}$

$\begin{array}{llr}3.4 & \text { Project Plan } & 18\end{array}$

$\begin{array}{llr}3.5 & \text { Summary } & 18\end{array}$

Chapter 4 - Database Design $\quad 19$ 
$\begin{array}{llr}4.1 & \text { Conceptual Data Model } & 19\end{array}$

$\begin{array}{lll}4.2 & \text { Logical Data Model } & 21\end{array}$

$\begin{array}{llr}\text { 4.3 Data Sources } & 24\end{array}$

$\begin{array}{llr}\text { 4.4 Data Collection Methods } & 24\end{array}$

4.5 Data Scrubbing and Loading 24

$\begin{array}{lll}4.6 & \text { Summary } & 25\end{array}$

$\begin{array}{lr}\text { Chapter } 5 \text { - Implementation } & 27\end{array}$

$\begin{array}{lll}5.1 & \text { Data Creation and Preparation } & 27\end{array}$

$\begin{array}{lll}5.2 & 3 D & 32\end{array}$

$\begin{array}{lll}5.3 & \text { Service Area Analysis } & 35\end{array}$

5.4 New Urbanism and Geodesign Application 37

$\begin{array}{llr}5.5 & \text { Summary } & 38\end{array}$

Chapter 6 - Results and Analysis $\quad 39$

6.1 3D Modeling of the Study Area 39

6.2 Services Accessibility of the Study Area $\quad 41$

$\begin{array}{lll}6.3 & \text { Two Designed Scenarios } & 48\end{array}$

$\begin{array}{lll}6.4 & \text { Summary } & 55\end{array}$

Chapter 7 - Conclusions and Future Work $\quad 57$

$\begin{array}{lll}7.1 & \text { Conclusion } & 57\end{array}$

$\begin{array}{lll}7.2 & \text { Future Work } & 57\end{array}$

$\begin{array}{lr}\text { Works Cited } & 59\end{array}$ 


\section{Table of Figures}

Figure 1-1: The project's study area in City of Taif, Saudi Arabia ..........................2

Figure 2-1: Steinitz, C. (2012). A framework for geodesign: Changing geography by

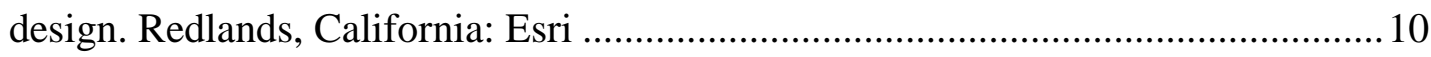

Figure 2-2: Kim, Lee, \& Randy (2009). New Urbanism Characteristics of Cherry

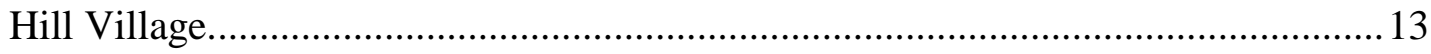

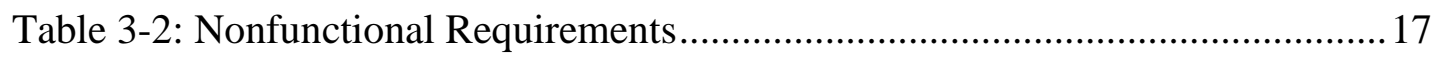

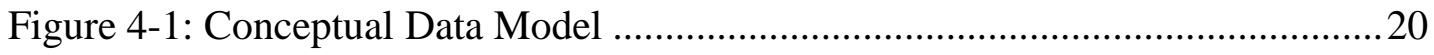

Figure 4-2: Conceptual Data Model .............................................................. 21

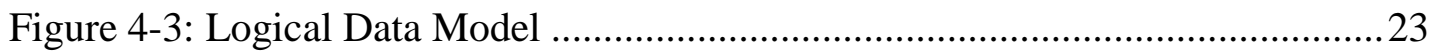

Figure 5-1: The Conversion from Excel Spreadsheet into ArcGIS Feature Class ....28

Figure 5-2: The Digitizing of the Building Footprints......................................... 30

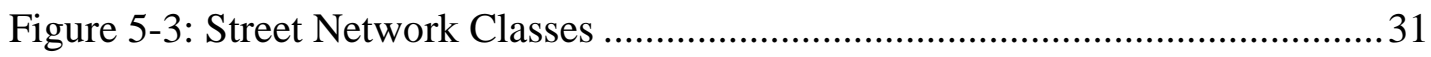

Figure 5-4: Adding Realistic Tree Symbology ................................................. 32

Figure 5-5: The Buildings With Designed Facades .................................................33

Figure 5-6: Importing COLLADA Files into SketchUp...................................... 34

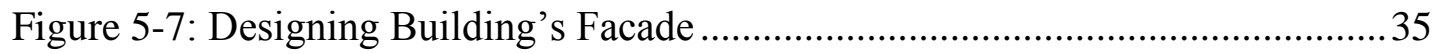

Figure 5-8: Defining the Network Dataset Attributes........................................... 36

Figure 6-1: 3D Example View of the Study Area.......................................... 40

Figure 6-2: The Facade design of the Three Buildings....................................... 40

Figure 6-3: Groceries Accessibility Analysis within 400 Meter ............................42

Figure 6-4: Health Facilities Accessibility Analysis within 1.5 Kilometers .............43

Figure 6-5: Malls Accessibility Analysis within 1.5 Kilometers............................ 44 
Figure 6-6: Mosques Accessibility Analysis within 400 Meter .

Figure 6-7: Parks Accessibility Analysis within 400 Meter................................... 46

Figure 6-8: Schools Accessibility Analysis within 400 Meter.............................. 47

Figure 6-9: The Current Land Uses and The Proposed Demolition Area ................ 49

Figure 6-10: The First Scenario for the Study Area .......................................... 51

Figure 6-11: The Second Scenario for the Study Area ....................................... 53

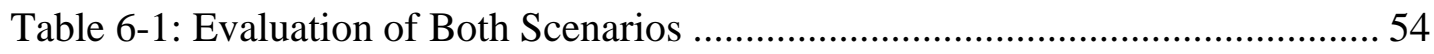

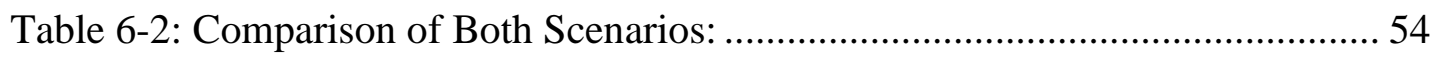




\section{List of Tables}

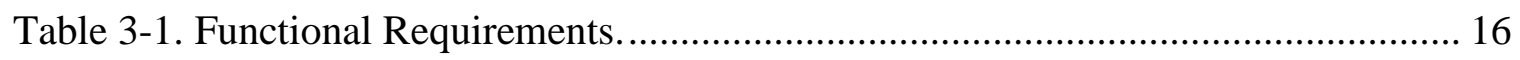

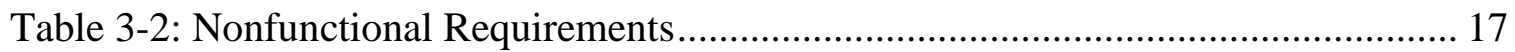

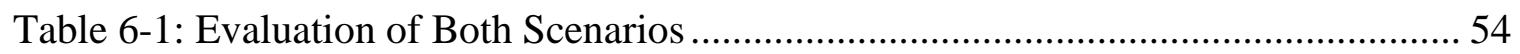

Table 6-2: Comparison The Added Land-uses of Both Scenarios: ................................ 54 




\section{Chapter 1 - Introduction}

The future vision of Saudi Arabia is to be a global investment powerhouse. As Saudi Arabia holds strong investment capabilities, the country is straightening its economy, as well as increasing revenues in several ways. These include developing and upgrading most of the country's tourist attractions and cities. According to the city's website, "Taif is a city located in the Mecca Province of the Western part of Saudi Arabia and is the center of an agricultural area known for its grapes, pomegranate, figs, roses and honey. A popular summertime vacation destination in the Kingdom, Taif offers fantastic views, hiking trails and cable cars, as well as a number of rose farms open to visitors and available for tours." Also, the city has a population of 1,200,000 people.

By applying modern technologies to Taif, the city will be able to address the needs of its citizens, visitors, and decision-makers. The use of geographic information system (GIS) technology has grown rapidly around the world. It lets decision-makers organize, manage, visualize, analyze, and understand relationships between data and patterns in order to answer their questions. Among the different GIS applications and tools, threedimensional (3D) modeling of cities is one of the common approaches used in urban planning and development (Li Yin, 2014). A 3D model allows users to better visualize, simulate, and illustrate the data as it would appear in the real world. According to the Esri website, "We live in a 3D world and many spatial questions can only be answered in 3D," (Esri, 2016). Also, the ArcGIS Network Analyst extension is an important tool for urban planners because it generates travel directions between locations, identifies the closest facility within a travel, calculates service areas around any given location on a street network, and proposes optimal locations for new services or facilities (Esri, 2016). 
Through this project, a 3D visualization, a service-accessibility analysis, two designed scenarios will be provided for the project's study area (Fiqure1-1).

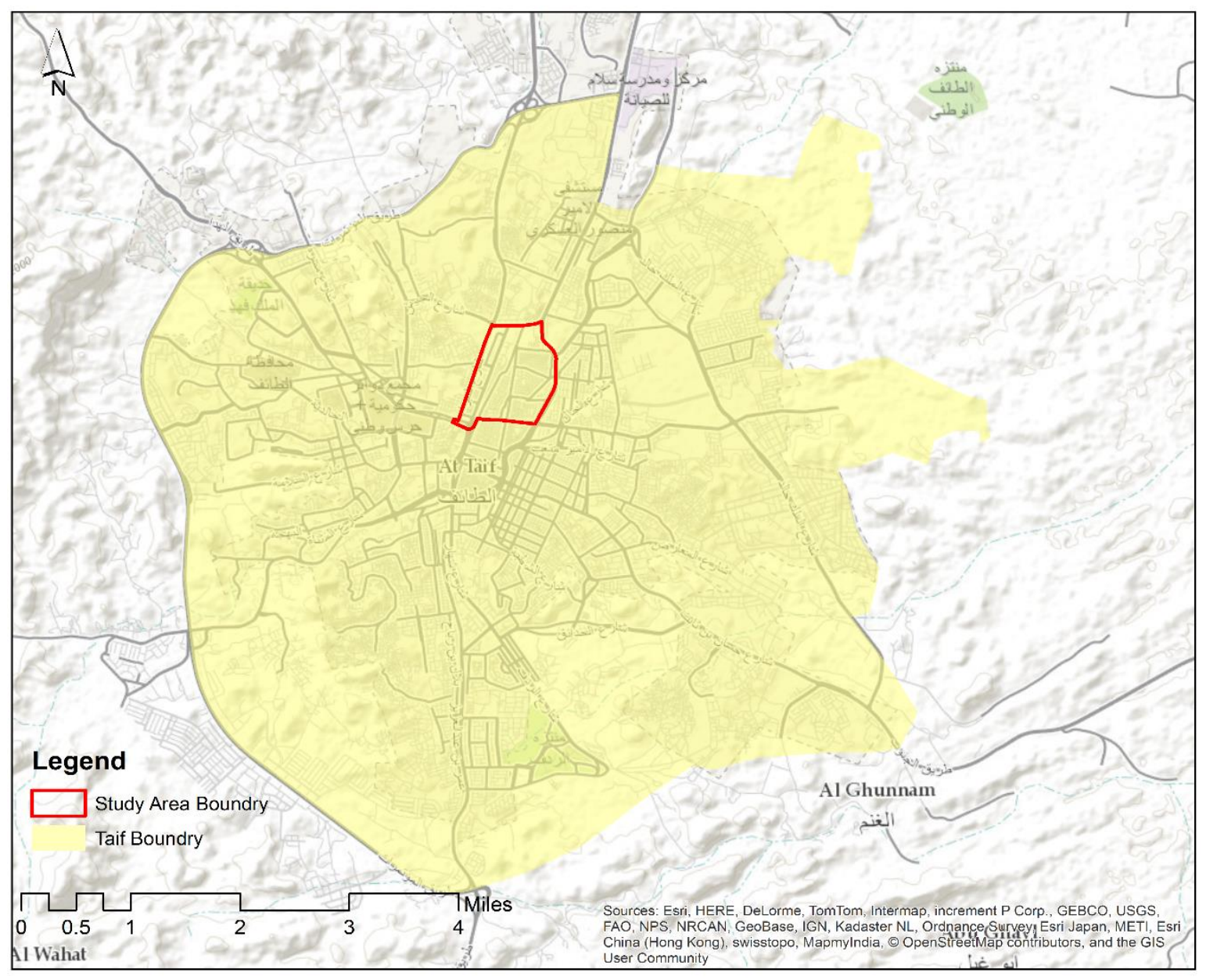

\section{Figure 1-1: The project's study area in City of Taif, Saudi Arabia}

\subsection{Client}

The client of the project is Al-Masaar, a private company. This company works in various fields of GIS and information technology (IT). It provides consulting services in many different areas such as cadastral mapping, land-use and zoning maps, survey plans, neighborhood and subdivision plans, spatial analysis \& geospatial analysis, 3D modeling and analysis, urban regeneration analysis, and transportation analysis. The client is often 
involved in various phases of a project such as execution, design, implementation, application, and technical support.

\subsection{Problem Statement}

The Taif municipality and Al-Masaar Company lacked a three-dimensional model of the specified area in the city, as well as evaluate the study area's services accessibility. The

3D model would allow them to have an actual simulation of the study area to understand the study area quickly, attain better results of their current and future urban design projects, and observe whether areas are under heavy use or not. Also, analyzing the study area's service accessibility was critical in order to provide information that would help them to evaluate and change existing services or locate new services or facilities. In other words, the client wanted to be able to obtain a complete picture of the impact of new service locations or of a proposed development.

\subsection{Proposed Solution}

The proposed solution for the client's problem was to provide a 3D visualization of the

study area, using ArcGIS Network Analyst, and applying the principles and techniques of geodesign and New Urbanism concepts. The first phase of the solution, 3D visualization, involved using ArcGIS Pro for creating virtual buildings and trees within the study area. The ArcGIS Network Analyst extension was used for the second phase of the solution. This extension identified routes between locations and facilities, provided information about distance and drive-time, and calculated service areas for the study area. Then, geodesign techniques and New Urbanism principles were applied to the study area, which helped the client evaluate proposed development and put new services and facilities in 
strategic locations. In future, this solution will offer valuable information about the study area, which will lead to finding the optimum locations for new development.

\subsubsection{Goals and Objectives}

The goals of this project were to develop a 3D model for the study area components such as buildings and trees, as well as design two different scenarios through service area analysis. These goals were achieved through the implementation of the following:

1. A geodatabase for the study area of the project to store all data

2. A 3D model for the study area that represent buildings, trees, and some buildings' facades via ArcGIS Pro

3. ArcGIS Network Analyst to calculate services area of facilities

4. Two proposed design scenarios to depict upgrading existing services and locating new services and activities in the study area, based on the techniques and the principles of geodesign and New Urbanism

\subsubsection{Scope}

The solution that was proposed for this project was focused on creating a 3D web map based on 2D data that was digitized in usable formats for ArcGIS software such as ArcMap and ArcGIS Pro. With this software, the objectives of the project-3D modeling, network analysis, and two design scenarios—-were reached.

\subsubsection{Methods}

Creating the project's product required many different tasks, starting with exploring the data that were received from the client. The next step was to refine the data and identify what data were needed to achieve the project's objectives. In ArcMap, the data needed to 
be converted, digitized, and prepared to be in a usable format. A geodatabase was designed and included all necessary features such as the building footprints, trees, streets, and the Network Analyst dataset. A 3D model was generated based on heights of the 2D data that had been prepped. Then, the $2 \mathrm{D}$ data was converted to 3D data by ArcGIS Pro, using the Network Analyst geoprocessing tool. Also, geodesign techniques and New Urbanism principles were applied to the study area to calculate and analyze the accessibility of services for the neighborhood/town residents.

\subsection{Audience}

The targeted audience for this project consists of the client's GIS professionals, faculty and students, city planners and designers, decision-makers, and people who are interested in 3D modeling and geodesign analysis.

\subsection{Overview of the Rest of this Report}

The rest of this report is organized into six chapters to provide details and information about all the project's parts. Chapter 2 discusses some previous projects and research that were used for 3D model as well as Network analyst, geodesign, and New Urbanism. Chapter 3 defines the system design, the project plan, and the project requirements. Chapter 4 covers the database design, the conceptual data model, and the logical data model. Chapter 5 explains and details the entire workflow of the project including all the work that was done to solve the client's problem. Chapter 6 shows the outputs and the results from the work described in of chapter 5. Chapter 7 provides a summary of the project and conclusions as well as recommendations for future work. 



\section{Chapter 2 - Background and Literature Review}

This chapter considers various examples of the four techniques implemented to solve the client's problem. The first technique was to create a 3D GIS model to visualize the study area's features as they exist in the real world, and that is addressed in section 2.1. Section 2.2 explains how ArcGIS Network Analyst was used to define the routes between locations as well as provide critical information about the routes. Other techniques, geodesign methods, and New Urbanism principles were used to provide the suitable scenarios for the study area. These techniques are discussed in the sections 2.3 and 2.4, followed by a summary at the end of this chapter.

\subsection{D GIS Modeling}

Since the world is not flat, it is necessary to map it in three dimensions to explore and understand development projects. In recent years, the use of 3D technologies has grown rapidly around the world. It offers a true perspective of the existing world components. Most 3D software is limited to create, edit, and visualize (Esri, 2016). However, 3D GIS modeling software, such as Esri CityEngine, ArcScene, and ArcGIS Pro, enables users to create, edit, visualize, analyze, and share data. Moreover, decision-makers and city planners are able to obtain effective and efficient results of their projects by performing spatial analysis, and they are able to publish their 3D model on the web to engage people and get citizens, recommendations and opinions (Esri, 2016).

The Hawaii Office of Information Management and Technology created a 3D GIS building model for Honolulu (State of Hawaii, 2014). This model covers about 25 square kilometers and includes 19,500 buildings. This model was made by CyberCity 3D based 
on stereo aerial imagery. The model simulated the buildings of the study area, depicting them as they were in the real world. The model was implemented to provide useful information to the governor in order to address sustainability in the state's comprehensive plan for the future. Furthermore, the model was used to show the potential for installing solar panel system on the roofs of the city's buildings.

\subsection{ArcGIS Network Analyst Extension}

Esri provides a tool that allows users to create a network spatial analysis to solve complex routing problems. This tool enables users to implement analysis over the street network in order to illustrate unique network requirements. Through the ArcGIS Network Analyst extension, users are capable of establishing routes for their entire fleet, including finding the most efficient travel route, providing information about routes' drive times, determining service areas based on time and distance, locating new services and facilities, and configuring solutions for other network-related problems (Esri, 2016).

The City of Chandigarh, India, implemented a project for identifying optimal routes between locations, as well as defining service areas based on distance and time, for different facilities such as hospitals, schools, and fire stations (Paveen Kumar, Dinesh Kumar, 2014). A Google Earth image of Chandigarh was used to digitize the road network and the locations of public services. These processes were created and generated with ArcGIS software. Then, the developers built a network dataset to work with the Network Analyst geoprocessing tool. By using this tool, the team determined the service areas of various facilities, and they identified the shortest routes between different locations. In fact, Network Analysis was critical for this project to measure the efficiency of services in terms of time and distance. Moreover, it assisted the decision-maker to 
locate new services based on the city's needs, and helped to determine the optimal routes between two locations, saving time and money (Esri, 2016).

\subsection{Geodesign Technology}

Geodesign is a set of concepts and processes that are based on geography, science, and design. It helps provide a framework for building city designs and plans by following natural systems. Carl Steinitz (2012), lays out a framework for geodesign projects that is shaped by these six key questions: How should the study area be described? How does the study area operate? Is the current study area working well? How might the study area be altered? What differences might the changes cause? and, How should the study area be changed?

According to Steinitz (1990), these questions should be iterated three times during any geodesign case study. from the first iteration, these questions should provide critical answers that help the geodesign team to understand the geographic study area, any problems and opportunities, and the scope of the study. For the second iteration, the questions should be asked in reverse order to help determine and identify the methods of the study. With the third iteration, as the geodesign team implements the study and provides results, they will be able to answer the what, where and when questions. After the geodesign team has completed the three iterations, they will have to make one of three possible decisions: yes, the project should procced; no, it should not; or maybe the project has merit, in which case more feedback and changes are needed from the geodesign team and the stakeholders. Figure 2-1 illustrates the Steinitz's framework for geodesign. 


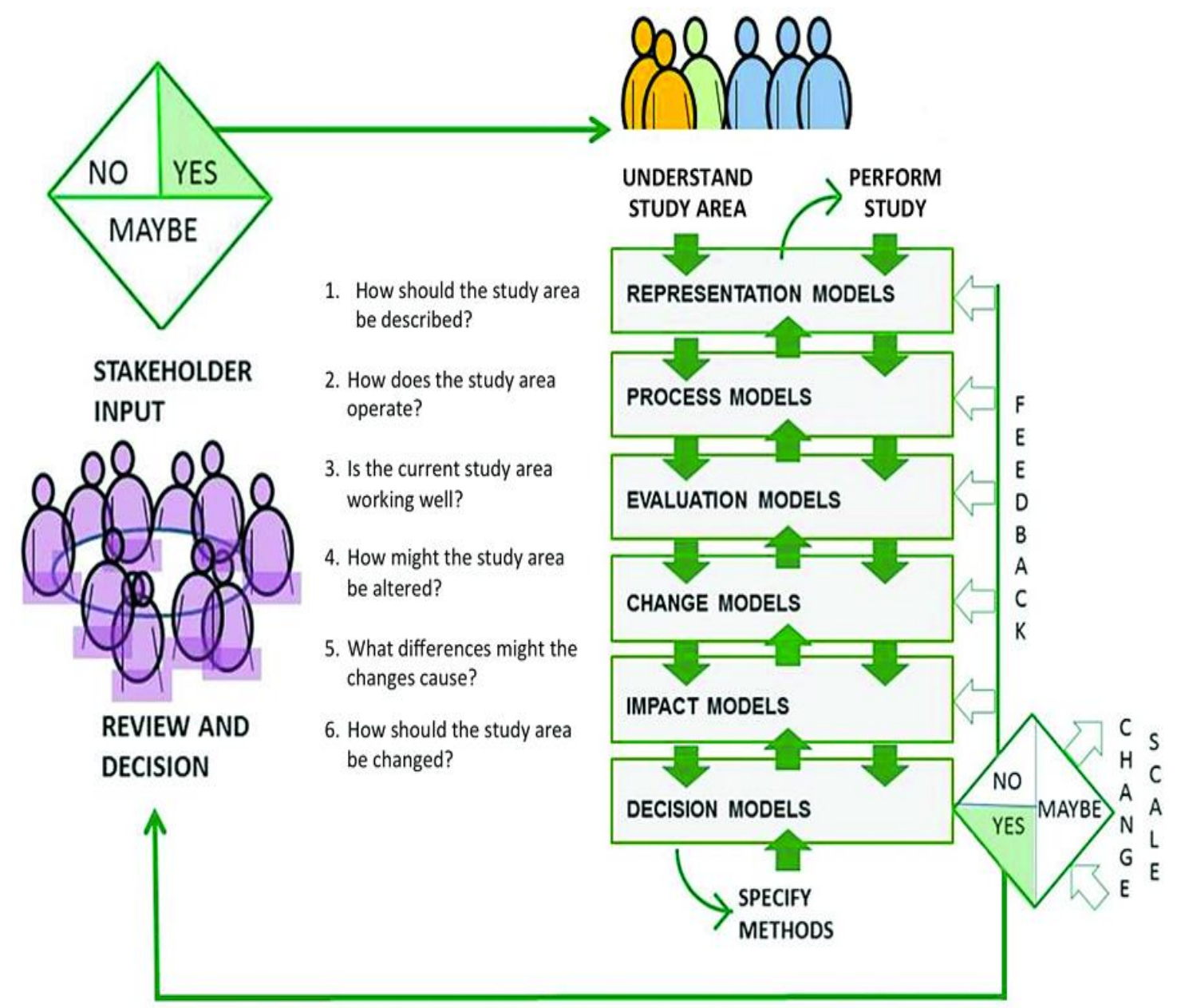

Figure 2-1: Steinitz, C. (2012). A framework for geodesign: Changing geography by design. Redlands, California: Esri

The combination of geodesign and GIS supports decision-makers in many different ways, such as allowing users to investigate and create alternative design scenarios for the future, and applyig 3D GIS technologies to facilities management, urban planning, and urban design (Esri, 2016). Alterative-design scenarios can be generated based on one or more kinds of GIS spatial analysis. For example, GIS Network Analyst can be used to user analyze neighborhood/town service-accessibility. In other words, 
Network Analyst helps users determine areas that need specific services such as schools, parks, and malls (Esri, 2016).

In an example of a combination of Geodesign and a GIS project, and according to Steinitz, C. (2012), the La Zone Industrial di Padova (ZIP) and the city of Padova, Italy, were interested in building a new park and industrial zone in the city (2006). The geodesign team was a group of people from different backgrounds and types of knowledge such as urban planners, designers, architects, and city designers. ZIP and the City of Padova clarified the project's scope, requirements, and time frame. The geodesign team applied a combinatorial change model to create alternative design scenaios based on more than one scale. A set of designs were created based on many factors such as transportation, industry, hydrology, heritage, and utilities. Through ArcGIS, the team created separate layers for each design. The geodesign team tested these designs by performing relative analyses based on the project requirements. This operation allowed the team to visualize, compare, combine, and consider many solutions for the study area. In the end, three appropriate scenarios were created by the geodesign team based on a number of designs, projects, and policy options.

\subsection{New Urbanism Principles}

The New Urbanism concept is centered on planning, creating, and developing based on the principles of how old cities, towns, and neighborhoods were built (New Urbanism, 2016). This approach focuses on the human scale in urban design, which involves including walkable streets and blocks, building shopping places and housing in close proximity, and creating accessible public spaces. Through this approach, people are able 
to live in sustainable cities, towns, districts, and places that offer a happy, healthy, and satisfactory life (New Urbanism, 2016).

According to Kyle (2006), New Urbanism can be efficient and effective guide for community development especially, for creating pedestrian-friendly communities. In other words, New urbanism helps to improve the level of neighborhood/town accessibility and connectivity for example, the most city services should be reached within at most a ten minutes walk of home and work. Also, most community's building should be close to streets with consideration of pedestrian's paths and the form of public spaces.

Kim, Lee, and Randy (2008) went to Cherry Hill Village, Michigan, to identify the design issues and solve them by applying New Urbanism principles. The team first explored the community designs and related problems and gathered the opinions of citizens, business owners, policy makers, and other urban planners. Based on this information, the team came up with several suggestions and recommendations in terms of community design and planning. Creating a walkable environment was the most needed change. For this purpose, the community plan included redesigning urban areas; creating and rebuilding streets; increasing the number of bicycle lanes and parking lots; and providing connections between walkways, bicycle lanes, and public transportation. As a result of these implementations, streets became safer, local businesses grew, the crime rate fell, traffic congestion was reduced, community activities increased, and the quality of life was enhanced. Figure 2-2 shows photos of New Urbanism characteristics of Cherry Hill Village. 


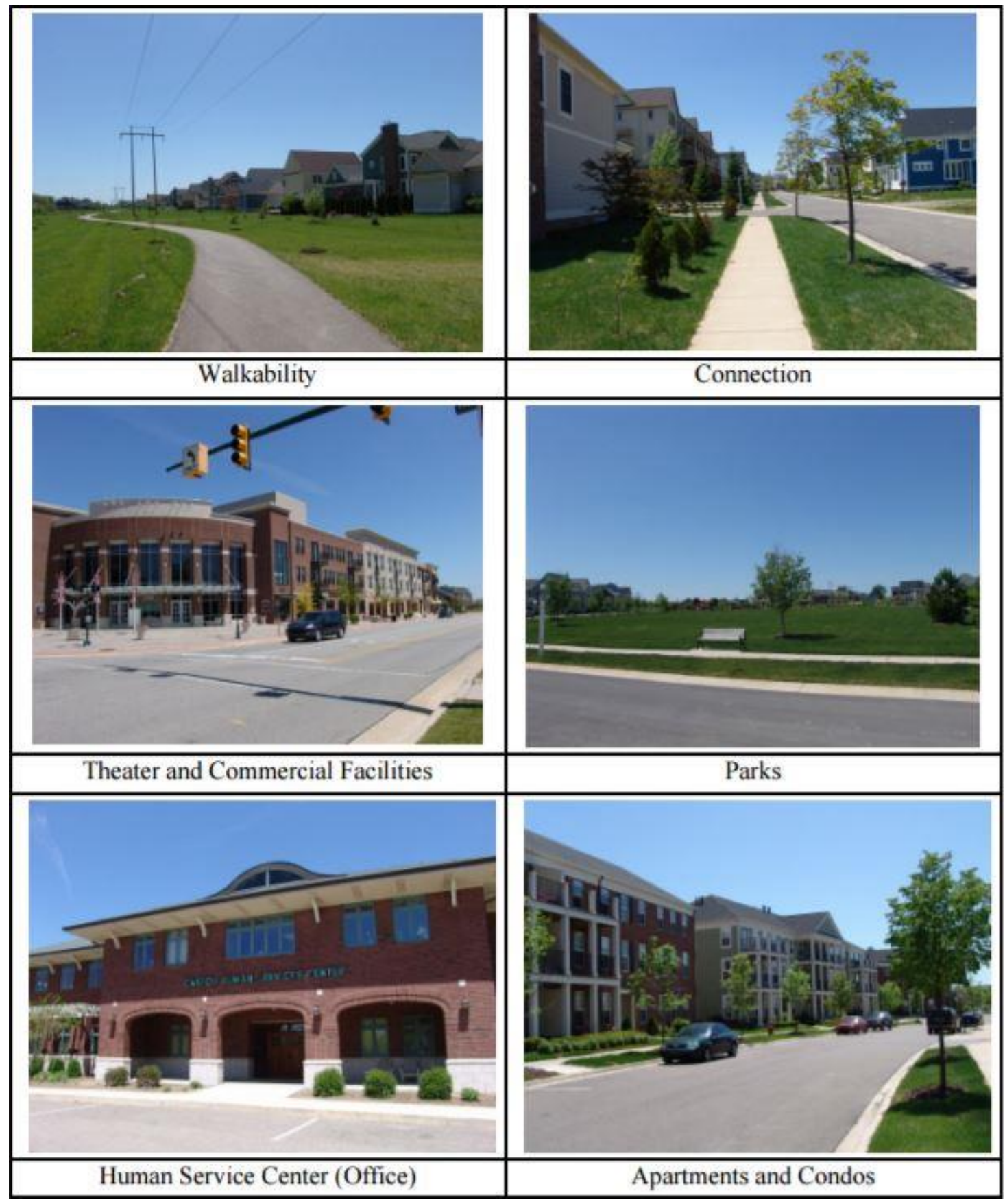

Figure 2-2: Kim, Lee, \& Randy (2009). New Urbanism Characteristics of Cherry Hill Village. 


\subsection{Summary}

In conclusion, this chapter discusses the combination of the previous four approaches led to the optimal solution for the client's problem in several sections. The first section described a project that used 3D technologies. The second section covered a project that performed network analysis. Also, the section thee and four explained the concept of geodesign and New Urbanism, as well as projects that used their methods. 


\section{Chapter 3 - Systems Analysis and Design}

This chapter identifies the system design and analysis that led to reaching the project's objectives as the client needed. The problem statement of the project is addressed in section 3.1. The project's requirements are covered in section 3.2. In section 3.3, the system design of the project is discussed. Section 3.4 describes the project plan. A summary of this chapter is provided in the last section.

\subsection{Problem Statement}

The city of Taif and Al-Masaar Company wanted to develop and upgrade most of the tourist attractions of the city, but did not have an accurate simulation of the study area

that help them evaluate and improve proposed development. Also, they needed relevant analysis to assist decision-makers and city planners while generating the most suitable development design for the study area in regards to residents access to their required services.

\subsection{Requirements Analysis}

Analyzing the requirements of the project was critical to achieve the project's goals and objectives. Both functional and nonfunctional requirements were included. The functional requirements specified the activities that the system must perform in order to accomplish what the client expected from the software or product. The nonfunctional requirements concentrated on the technical and operational aspects of the system. 
Table 3-1. Functional Requirements.

\begin{tabular}{|l|l|}
\hline Functional Requirements & Description \\
\hline Network Analyst & $\begin{array}{l}\text { This tool allows the user to perform road network and } \\
\text { service area analysis. }\end{array}$ \\
\hline Network Analyst dataset & $\begin{array}{l}\text { The product must a complete roads network dataset of } \\
\text { the project's study area. }\end{array}$ \\
\hline $\begin{array}{l}\text { Displaying 2D and 3D data } \\
\text { on one map }\end{array}$ & $\begin{array}{l}\text { The user has the ability to display and visualize the 2D } \\
\text { and the 3D data at the same time. }\end{array}$ \\
\hline Route optimization & The user can calculate the best route between locations. \\
\hline $\begin{array}{l}\text { Calculating distances and } \\
\text { drive time }\end{array}$ & $\begin{array}{l}\text { The user will be able to obtain information about how } \\
\text { far the locations are from each other, and how long } \\
\text { walking or driving will take. }\end{array}$ \\
\hline Calculating service area & $\begin{array}{l}\text { The user will be able to find service areas near any } \\
\text { location on the network. }\end{array}$ \\
\hline Editable 3D model & $\begin{array}{l}\text { The 3D model must be editable so that the user has the } \\
\text { ability to change, delete, create, and redesign the } \\
\text { project features. }\end{array}$ \\
\hline
\end{tabular}


Table 3-2: Nonfunctional Requirements

\begin{tabular}{|l|l|}
\hline $\begin{array}{l}\text { Non-Functional } \\
\text { Requirements }\end{array}$ & Description \\
\hline Esri ArcGIS Pro 1.2 & $\begin{array}{l}\text { Contains the geodatabase file, creates and edits the } \\
\text { data, and to uses the Network Analyst tool }\end{array}$ \\
\hline Operating System & $\begin{array}{l}\text { Windows 7, 64-bit operating system, 8 GB RAM, } \\
\text { and 3.00 GHz processor speed }\end{array}$ \\
\hline Data Format & All the final data configured for ArcGIS \\
\hline File Geodatabase & $\begin{array}{l}\text { Organizes the project data and contains Network } \\
\text { Analyst dataset }\end{array}$ \\
\hline Coordinate System & $\begin{array}{l}\text { Ain el Abd 1970 UTM Zone 38 used as a projection } \\
\text { system of the project }\end{array}$ \\
\hline
\end{tabular}

\subsection{System Design}

The project's data were prepared, edited, created, converted, and organized via ArcGIS

Pro 1.2. A file geodatabase was made to store and arrange all of the project's data. To build a 3D model, the z-values were added to the project's features such as the building footprints and trees. These 2D data were converted to 3D data in order to provide a 3D visualization for the study area. The Network Analyst data were created by ArcCatalog software and stored in the file geodatabase. Through ArcMap 10.3, Network Analyst was used for identifying routes, drive times, and distances between locations, as well as for 
calculating the service areas of facilities. Sketch Up software was used to accurately replicate city building facades. Then, Geodesign and the New Urbanism principles were employed in order to design scenarios for the study area.

\subsection{Project Plan}

The project plan was divided into four phases to help keep the project on track. Each phase depended on previously completed tasks. Planning was the first phase and included many different tasks, such as defining the project's scope, goals, and objectives;

Exploring the clients' data; collecting data, and determining all project data requirements. The second phase was design, which included data preparation, data conversion, and cleaning; identifying project methodologies; and creating a logical data model. The third phase was development, which involved technical tasks that included creating a file geodatabase, converting 2D data to 3D data, generating the 3D model, and using Network analyst. Deployment was the last phase, which involved testing and reviewing the project's elements and components to ensure that all tasks were completed and all of the project's objectives were achieved efficiently.

\subsection{Summary}

This chapter provided a brief review of the project's problem and discussed the requirements analysis and the project's design and plan. The requirements analysis identified both functional and nonfunctional requirements which led to creating the project's product. The system design clarified the main components of the project and how they could be implemented. The project plan covered the four phases of the project: planning, design, development, and deployment. 


\section{Chapter 4 - Database Design}

This chapter discusses the design of the system geodatabases (GDBs), and the data that were used to create this project. The conceptual data models are covered in section 4.1. The logical data model is described in section 4.2. Also, this chapter explains the data source, in section 4.3 , and section 4.4 outlines the data collection methods. Section 4.5 illustrates how the project's data were scrubbed and loaded into the database. Section 4.6 provides a summary of this chapter.

\subsection{Conceptual Data Model}

The conceptual data model provides one of the most important methods of defining the project's components and the relationships among them. This project contains two parts, 3D visualization and neighborhood services accessibility. Therefore, several components were considered, and two conceptual data models were created to determine each part's components. These conceptual data models illustrate how the project's components are related to each other.

The first model defines specific components that were used to create a 3D visualization of the study area. The components considered in this project include the Building's footprints, Trees, Streets Network, and Building's facades. Figure 4-1 shows the components of the first geodatabase, which contained the 3D visualization of the project's study area. 


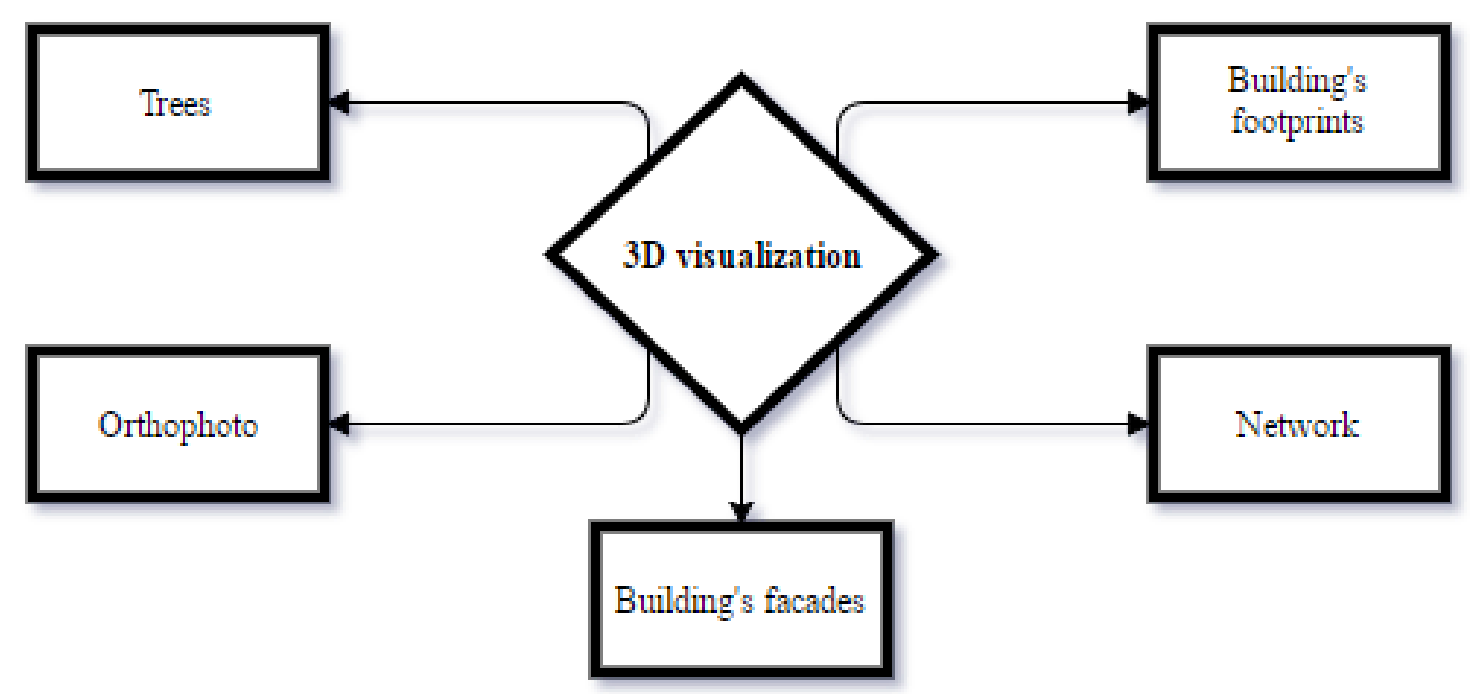

Figure 4-1: Conceptual Data Model

The second conceptual data model (Figure 4-2) was created to illustrate all the project analysis components. Through this conceptual data model, all inputs that were needed to perform the service area analysis are covered. These inputs were organized into two feature datasets: Network and Locations. The Network dataset consisted of transitions, routes, junctions, and stops. The Locations dataset consisted of any type of facilities that needed to calculate a service area: schools, parks, mosques, etc. 


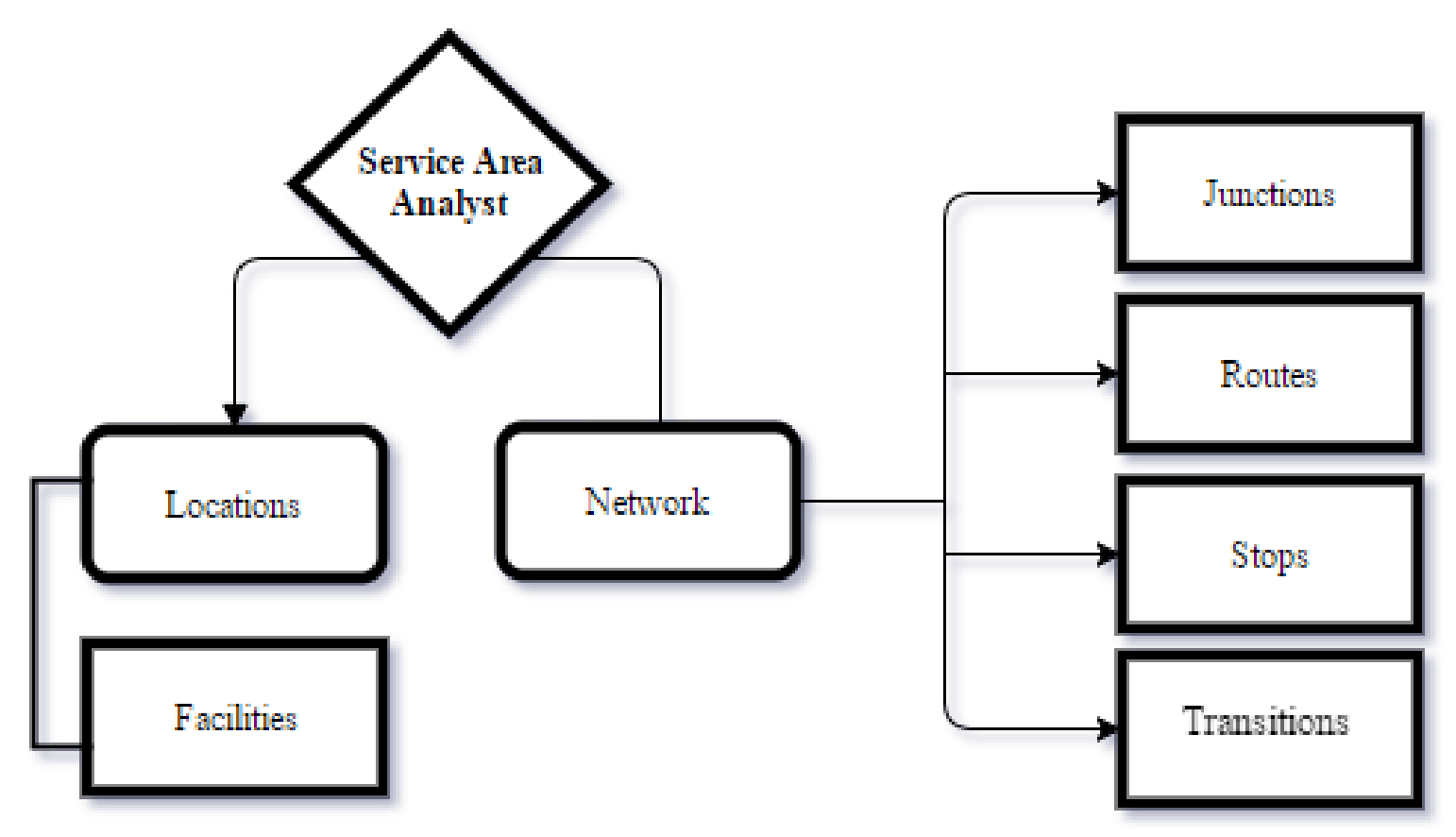

Figure 4-2: Conceptual Data Model

\subsection{Logical Data Model}

The logical data model takes the conceptual data models and describes them in more detail in order to construct a physical database. This project does not have a complex database, so the Esri file geodatabase format was used to design the project's database. The feature classes of each part of the project were organized into two feature datasets: $3 \mathrm{D}$ visualization and the Service area analysis. Also, the Network feature dataset was built in the project's GDB file in order to allow the ArcGIS Network Analyst extension to run and calculate the service area of facilities, and to contain all the network feature classes such Junctions and Stops. This logical data model consisted of a geodatabase file that contains all of the project's feature datasets and all the necessary attributes that were needed to build the 3D visualization and calculate the facilities' service areas. Moreover, 
Esri's World Imagery layer was used as a basemap for the study area, and it was hosted in the geodatabase file of the project.

The 3D Visualization feature dataset included five feature classes: Building's Footprints, Trees, Streets Network, Building's Facades, and Basemap. The Building Footprints polygon feature class was two-dimensional (2D) before it was converted into three-dimensional (3D) based on the building heights. The attributes of this feature class had some important fields such as building heights, land use, and floor numbers. Also, the land use field had six subtypes: Educational, Residential, Commercial, Health, Government, and Religious. The 2D Trees point feature class was used to represent the location of the study area trees, and to convert them to 3D. The Streets Network polyline feature class had four subtypes: Highway, Primary, Secondary, and Unpaved. Furthermore, it had significant attribute fields that were used for the analysis such as street speed and street length. The Building's Facades multipath feature class was used to show the facades of the biggest mall, the tallest building, and a well-known mosque in the city.

The Service Area Analysis feature dataset contained all the generated service area polygons of the study area facilities such as schools, parks, malls, markets, mosques, and government departments. Those polygons represented the service area of the facilities; the service area was calculated and published at a specific distance, 400 meters, based on roads speeds and lengths. Figure 4-3 shows the logical data model that was used for this project. 

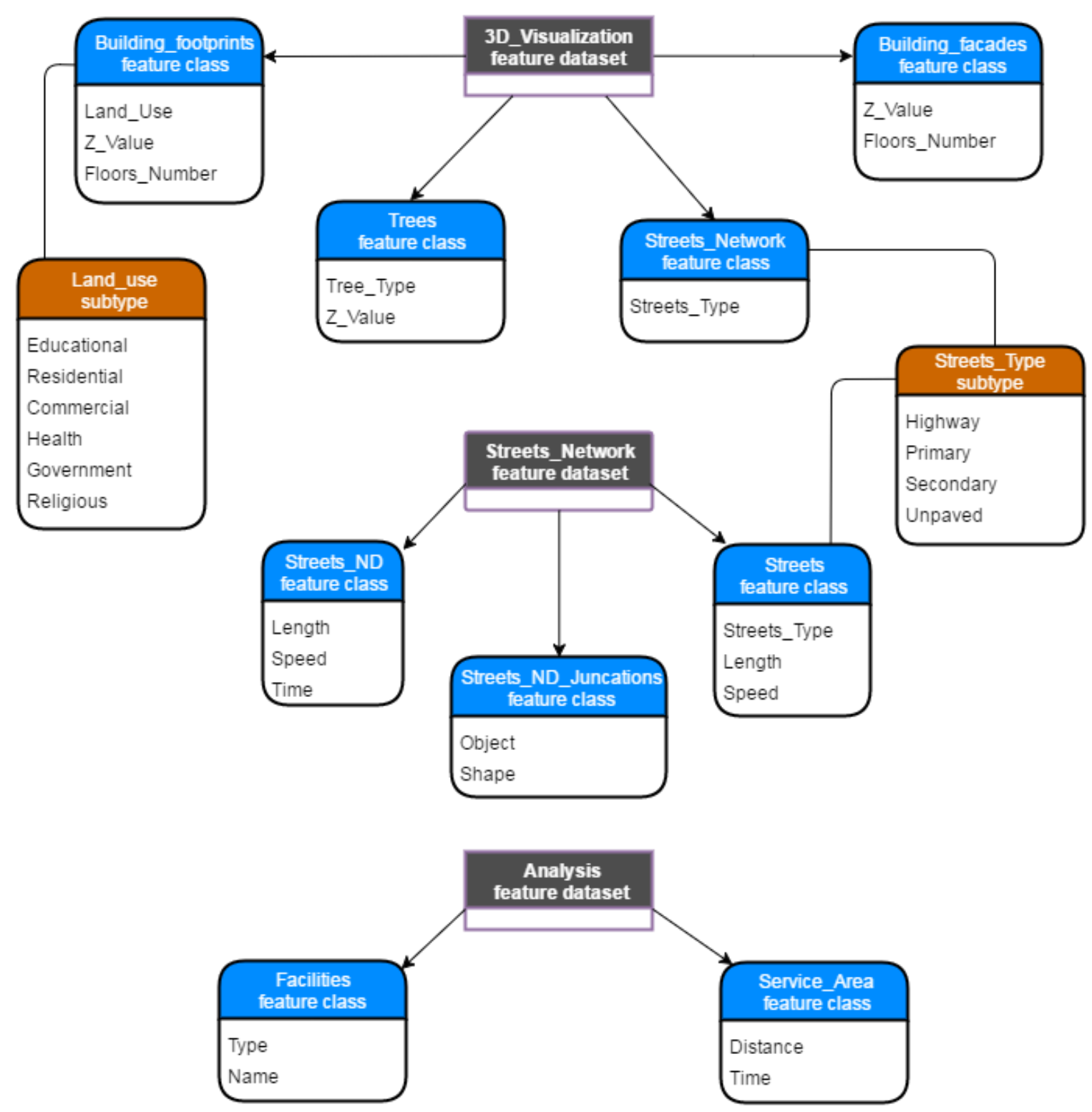

Figure 4-3: Logical Data Model 


\subsection{Data Sources}

Most of the data that were used in this project were provided by the client, Al-Masaar Company, and the rest of data was digitized via ArcGIS Pro. The data provided were shapefiles and excel spreadsheets. Most shapefiles such as Schools, Shopping centers, Hotels, Health facilities, Government departments, and Mosques, were points; the Street Network shapefile was polyline. The rest of data was in excel spreadsheets that contained information about the types of land use such as educational, residential, commercial, health, government, and religious. Also, $\mathrm{x}, \mathrm{y}$, and $\mathrm{Z}$ coordinates were included for each parcel in excel. All the data were received online through e-mail.

\subsection{Data Collection Methods}

The data collection method for the project's data was straightforward. All the data were downloaded through multiple e-mails from the client and transferred to an external hard drive. The building's footprints feature class is the only one that was digitized in order to achieve the project's objectives. This feature was digitized based on the Esri's world imagery basemap.

\subsection{Data Scrubbing and Loading}

Since the data received from the client were in shapefile and excel formats, data scrubbing was essential in order to organize it and store it in a file geodatabase. First, all the excel spreadsheets were imported to ArcGIS Pro as map layers based on x,y events. Then, these map layers were exported into the geodatabase file of the project as point feature classes. Also, all the other shapefiles were imported into the geodatabase file. Some of the geodatabase's feature classes needed to be cleaned. For instance, the streets network feature class had a bigger network data than the study area, and some of the data 
needed to be deleted. Also, this feature class needed to include more attribute fields that were required for performing the analysis. Likewise, a polygon feature class was created to digitize the building footprints. Based on the client's knowledge, several subtypes were added into the building's footprints and the streets feature classes in order to represent each street's type and each building's use. The coordinate system chosen by the client for the project's GDB and its feature classes was Ain_el_Abd_UTM_Zone_37N.

\subsection{Summary}

Throughout this chapter, the database design of the project was addressed. The section about the conceptual data model explained the project's components and their relationship to each other within the database. The logical data model section discussed how the physical database was constructed based on the conceptual data model. The data sources section covered how the project's data were received. The data collection methods section described what methods were used to collect the project's data. Section 4.5 explained the data scrubbing and loading processes that were used to clean and prepare the project's data. 



\section{Chapter 5 - Implementation}

This chapter covers all the implementation methods that were used to create the $3 \mathrm{D}$

model of the study area, evaluate the neighborhood services' accessibility, and design

two scenarios. This chapter consists four sections including data creation and preparation

(section 5.1), 3D modeling (section 5.2), service area analysis (section 5.3), and scenario design in section 5-4.

\subsection{Data Creation and Preparation}

First, a file geodatabase was created in order to host, manage, and organize all the project data. This was fulfilled through several operations such as data conversion, data cleaning, and data adding. All the excel spreadsheet data had $\mathrm{x}$ and $\mathrm{y}$ coordinates, so the data were imported to ArcGIS Pro as event layers then they were converted into point feature class format via the conversion tools of the ArcGIS Pro data management toolbox (figure 5-1). All the shapefile data were imported and organized into the file geodatabase. 


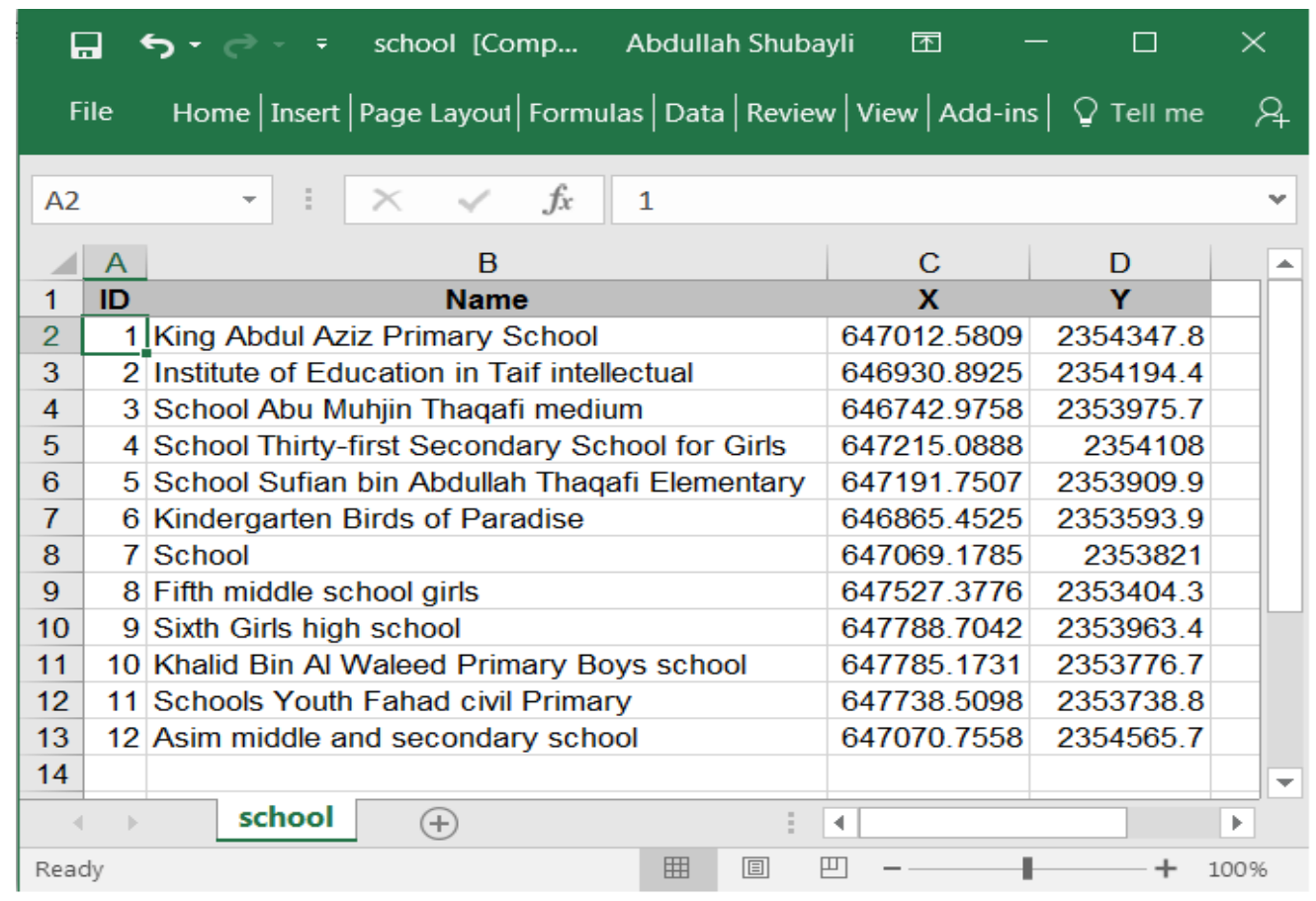

\begin{tabular}{|c|c|c|c|c|c|}
\hline \multicolumn{6}{|c|}{ Table } \\
\hline \multicolumn{6}{|c|}{ 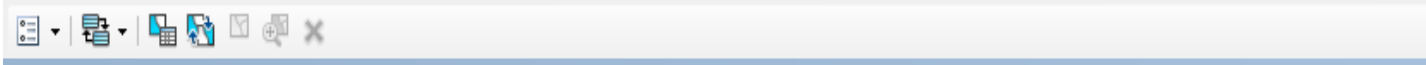 } \\
\hline \multicolumn{6}{|c|}{ Schools } \\
\hline & OBJECTID * & Shape * & Name_E & $\mathrm{X}$ & Y \\
\hline & 1 & Point & King Abdul Aziz Primary School & 647012.5809 & 2354347.7949 \\
\hline & 2 & Point & Institute of Education in Taif intellectual & 646930.8925 & 2354194.394 \\
\hline & 3 & Point & School Abu Muhjin Thaqafi medium & 646742.9758 & 2353975.6659 \\
\hline & 4 & Point & School Thirty-first Secondary School for Girls & 647215.0888 & 2354107.9797 \\
\hline & 5 & Point & School Sufian bin Abdullah Thaqafi Elementary & 647191.7507 & 2353909.9333 \\
\hline & 6 & Point & Kindergarten Birds of Paradise & 646865.4525 & 2353593.8502 \\
\hline & 7 & Point & School & 647069.1785 & 2353821.0389 \\
\hline & 8 & Point & Fifth middle school girls & 647527.3776 & 2353404.3242 \\
\hline & 9 & Point & Sixth Girls high school & 647788.7042 & 2353963.4344 \\
\hline & 10 & Point & Khalid Bin Al Waleed Primary Boys school & 647785.1731 & 2353776.7422 \\
\hline & 11 & Point & Schools Youth Fahad civil Primary & 647738.5098 & 2353738.7502 \\
\hline & 12 & Point & Asim middle and secondary school & 647070.7558 & 2354565.6825 \\
\hline
\end{tabular}

Figure 5-1: The Conversion from Excel Spreadsheet into ArcGIS Feature Class

For cleaning and adding data, most of the feature classes contained unwanted data pertaining to the area surrounding the project's study area. These types of data were selected by the attribute selection tool and deleted from each feature class. Also, as a few 
feature classes had redundant attributes and fields, removing data and rearranging rows and columns was required. Last, a polygon feature class were created in order to digitize the buildings' footprints. Several subtypes were assigned in the feature class that represented the land use for each building include: residential, government, commercial, health, green area, and educational. The land use and the height data for each building's footprint were copied and transferred from the converted point feature classes of the client's data. Figure 5-2 shows the digitized building footprints and their uses. Also, the streets feature class was categorized into three classes based on speed limits such as highway, primary, and secondary. Figure 5-3 illustrates the streets feature class and their types. 


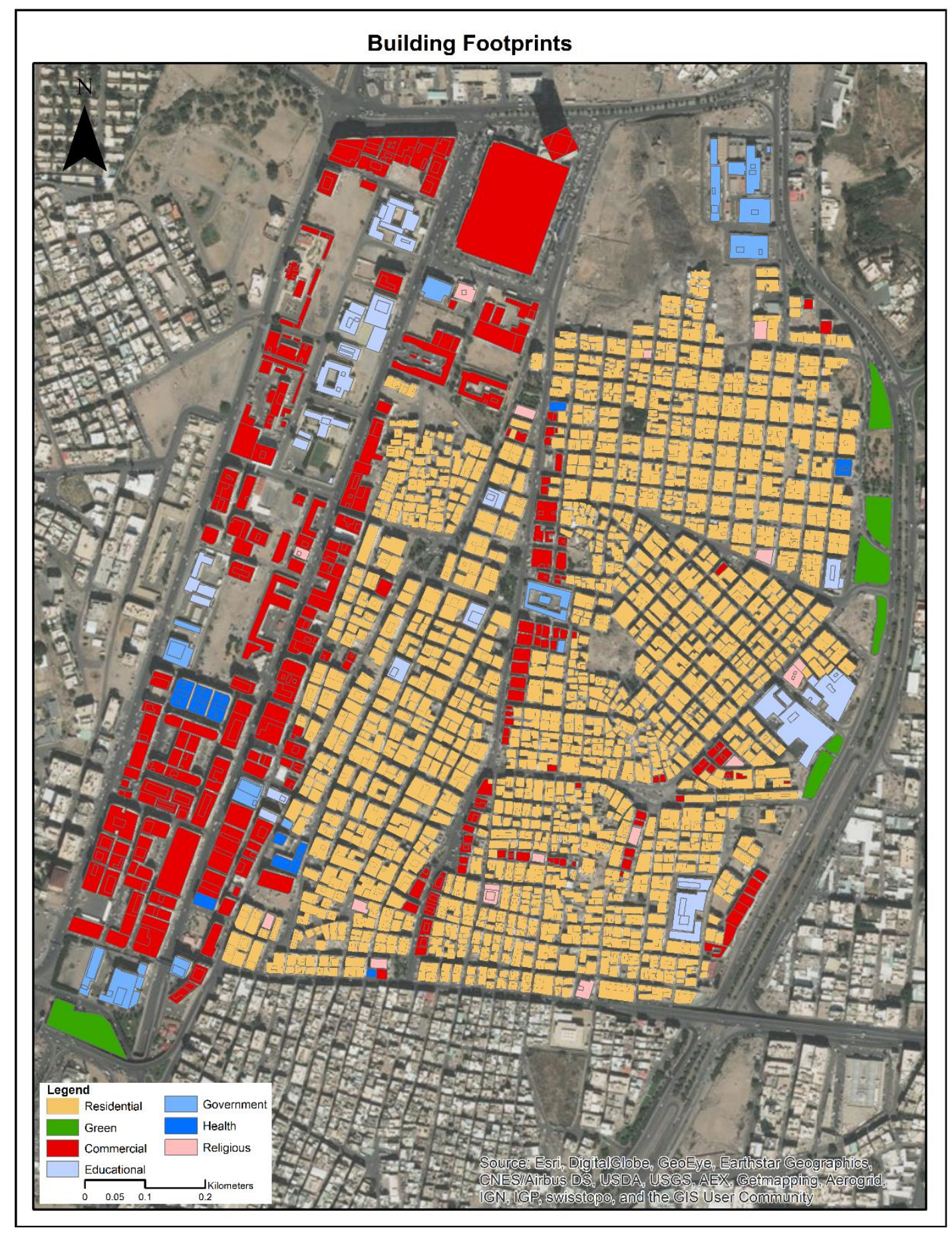

Figure 5-2: The Digitizing of the Building Footprints 


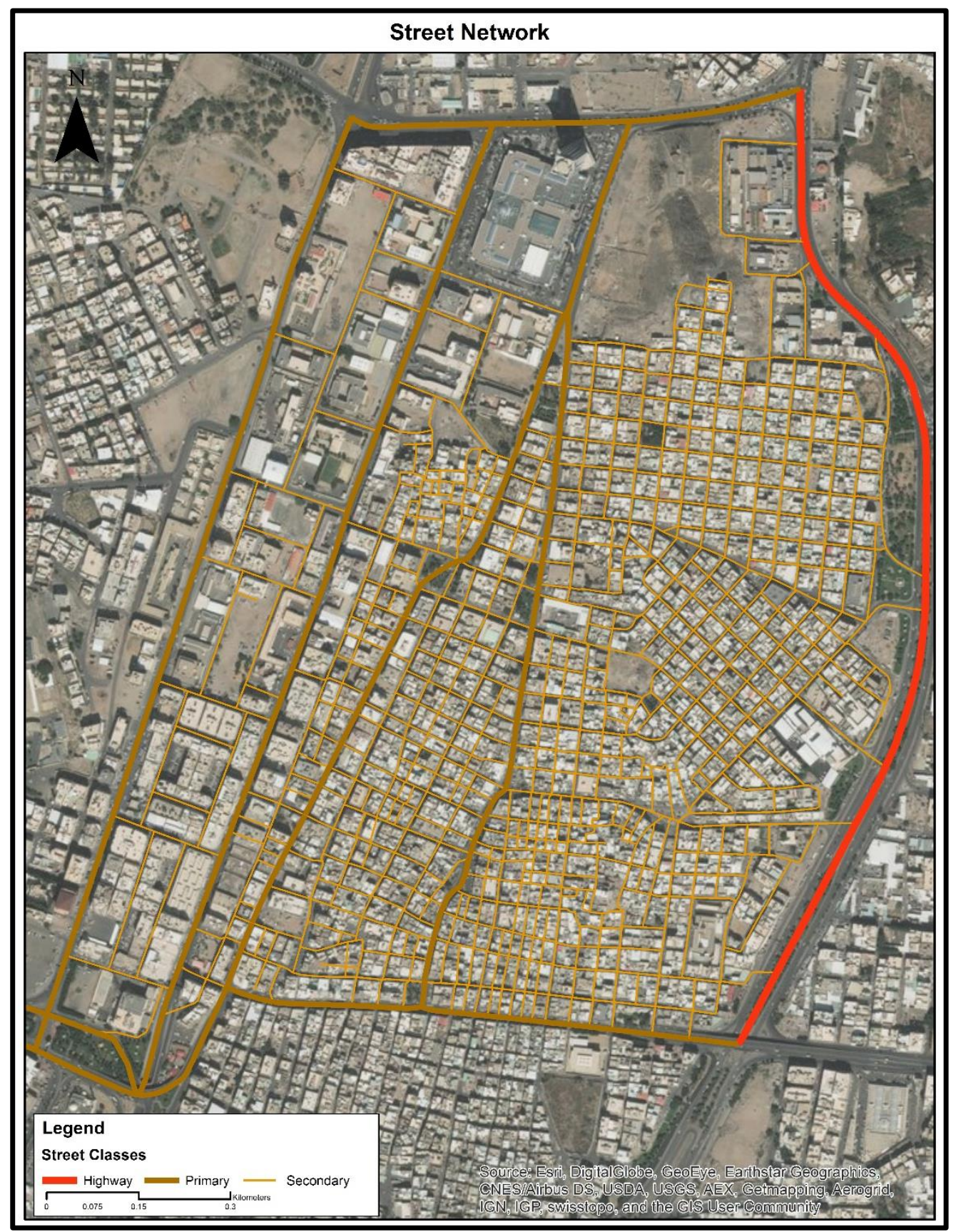

Figure 5-3: Street Network Classes 


\subsection{D modeling}

$3 \mathrm{D}$ visualization is one of the project's objectives, which were discussed in chapter 1.

This objective required several steps in order to meet the client's expectations. First, the digitized feature class, the Building footprint, was converted via ArcGIS Pro from 2D to 3D based on the z-values, the buildings' heights. This feature layer was specified to display on the ground through the layer properties because, naturally buildings belong on the ground. The above steps were also applied to the Trees feature layer. Using the ArcGIS Pro preset layer symbology, Realistic Trees view was displayed. Two types of the realistic tree symbologies, Palm and Elm, were chosen based on the client recommendations (figure 5-4).

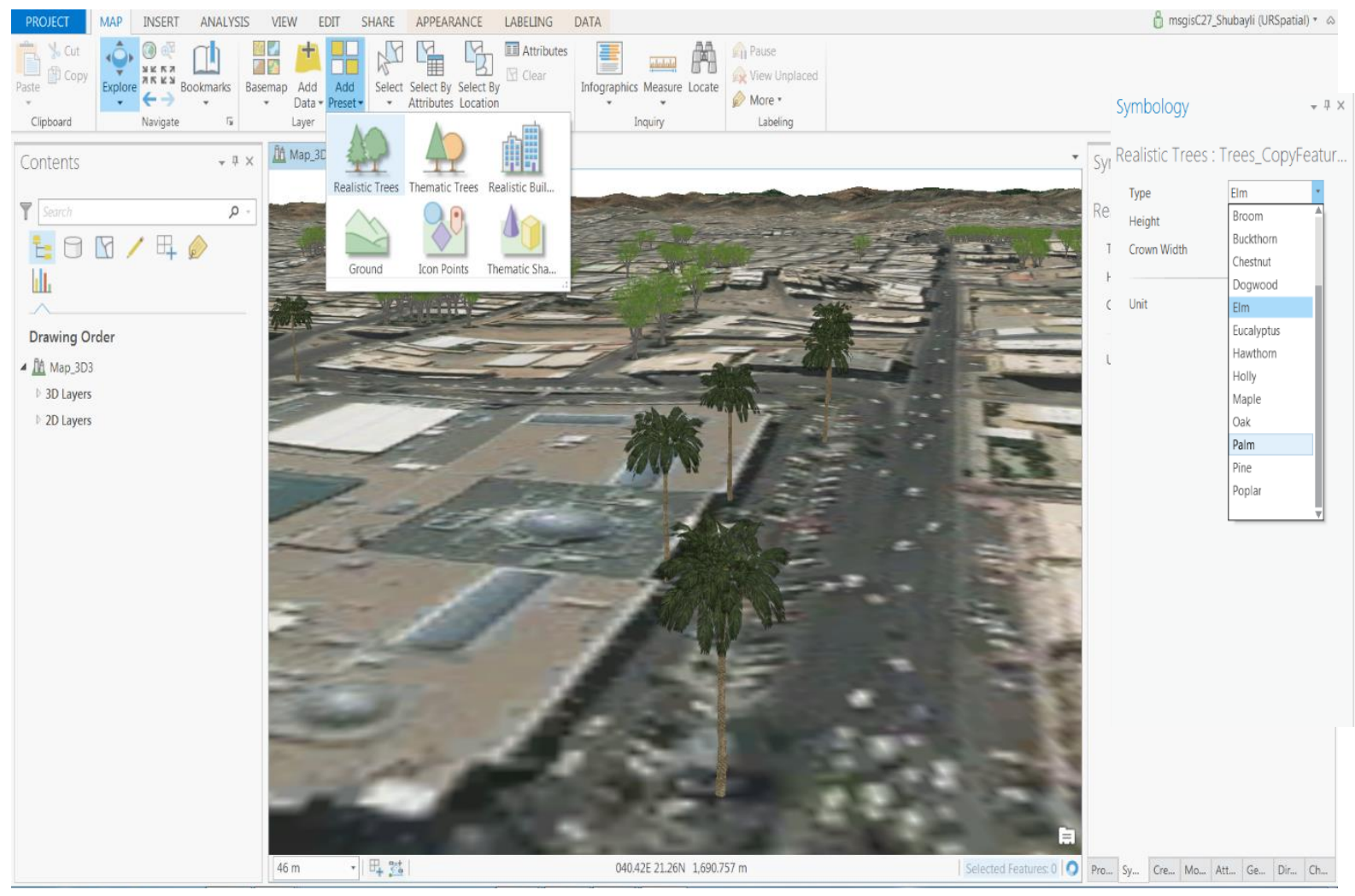

Figure 5-4: Adding Realistic Tree Symbology 
After that, SketchUp software was used to design the facades of the three known buildings of the study area: the tallest hotel, the well-known mosque, and the biggest mall (figure 5-5). These buildings' facades were created based on several processes. First of all, these three buildings were converted from a polygon feature class to a multipatch feature class. Next, this feature class was converted into Collaborative Design Activity (COLLADA) files; each file had one building in order to be opened and used in SketchUp software (figures 5-6 and 5-7). After these buildings were designed, they were exported and saved in SketchUp version 5 because it is the only version that is supported by ArcGIS software.

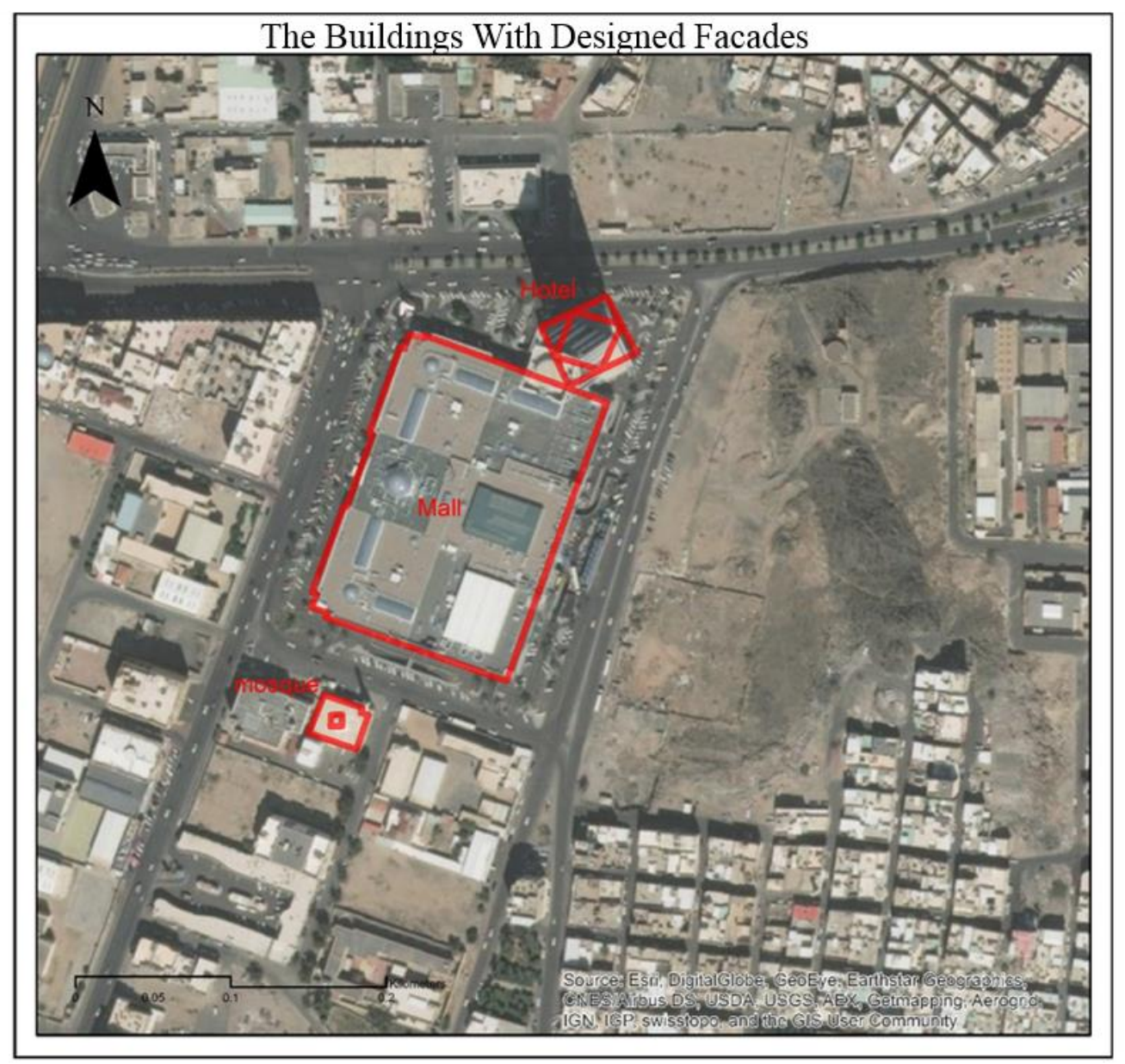

Figure 5-5: The Buildings With Designed Facades 


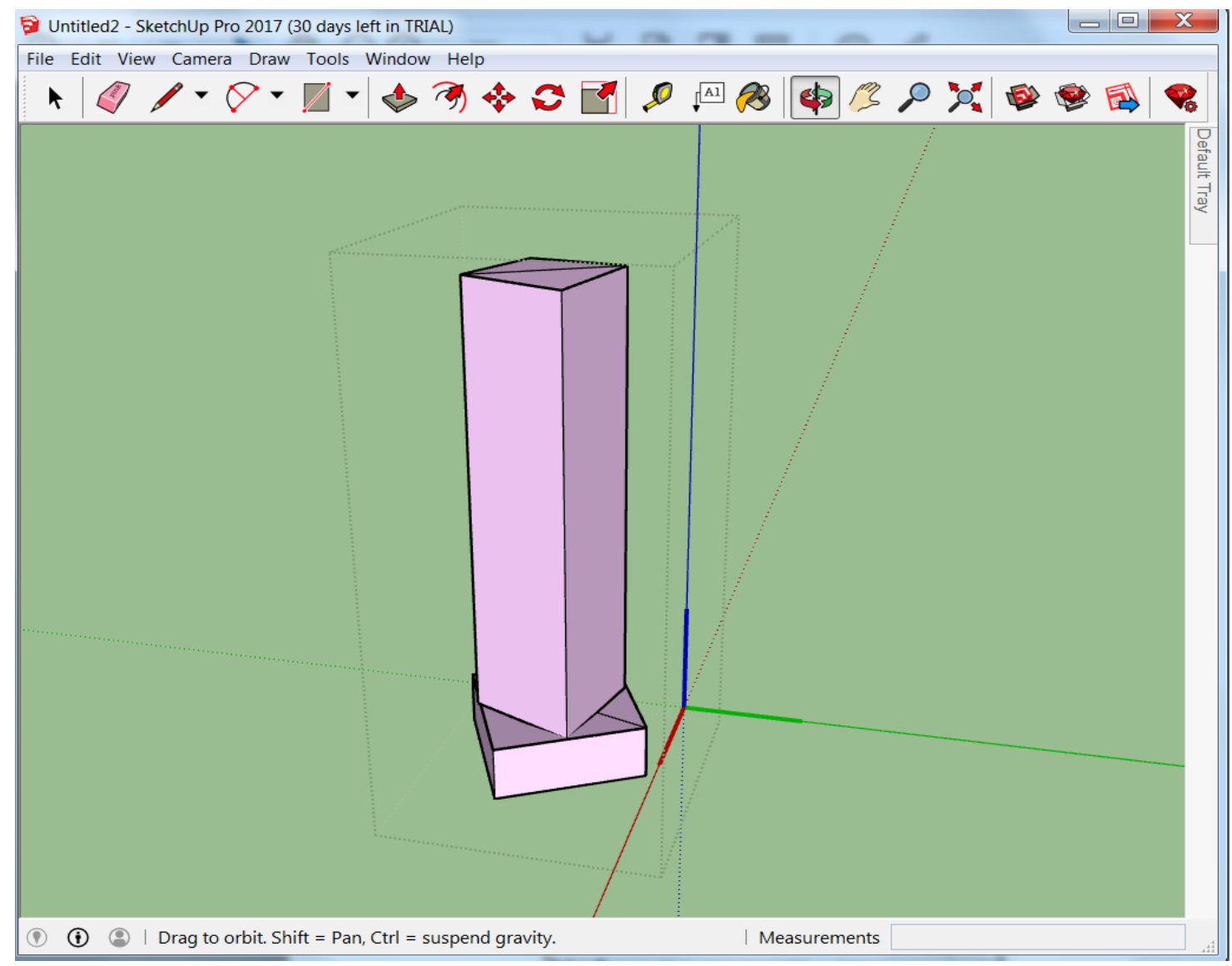

Figure 5-6: Importing COLLADA Files into SketchUp 


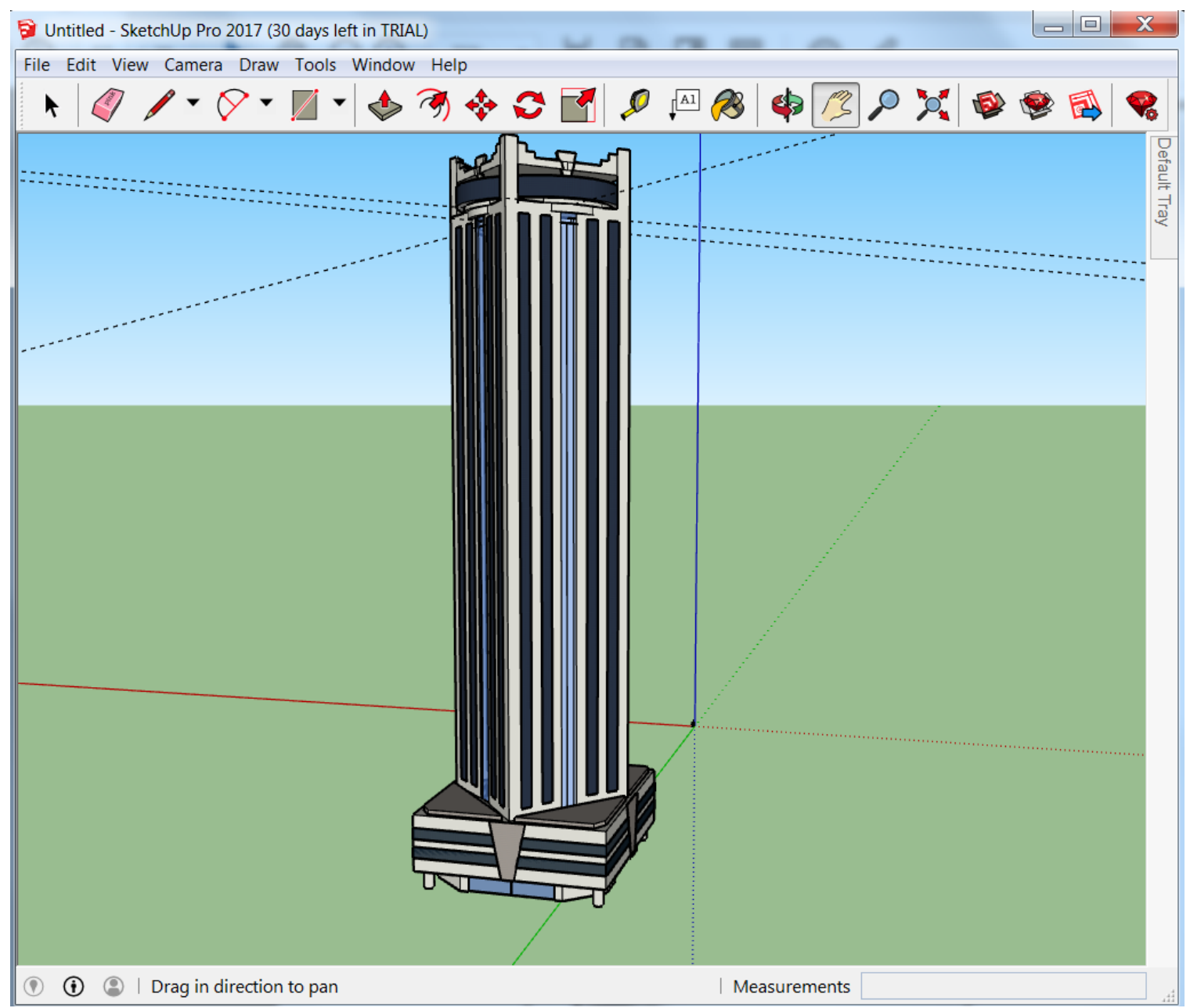

Figure 5-7: Designing Building's Facade

\subsection{Service Area Analysis}

ArcGIS Network Analyst was required to analyze and calculate the service areas of the study area facilities in order to determine whether areas are underserved. To perform this analysis, creating a network dataset was essential. This network dataset was built from the Streets feature class stored within the project's geodatabase. After that, the network attributes and the connectivity rules were defined for the network dataset (figure 5-8).

Fields for walk time and speed were added to the network dataset in order to calculate the service area for each facility, based on specific estimated distances, which are discussed 
in the following section. The service area distances were chosen based on the New Urbanism principles, which are discussed in chapter 2, and the project adviser's knowledge. This analysis was applied to all the services data that were received from the client, including schools, parks, hospitals, groceries, malls, and mosques.

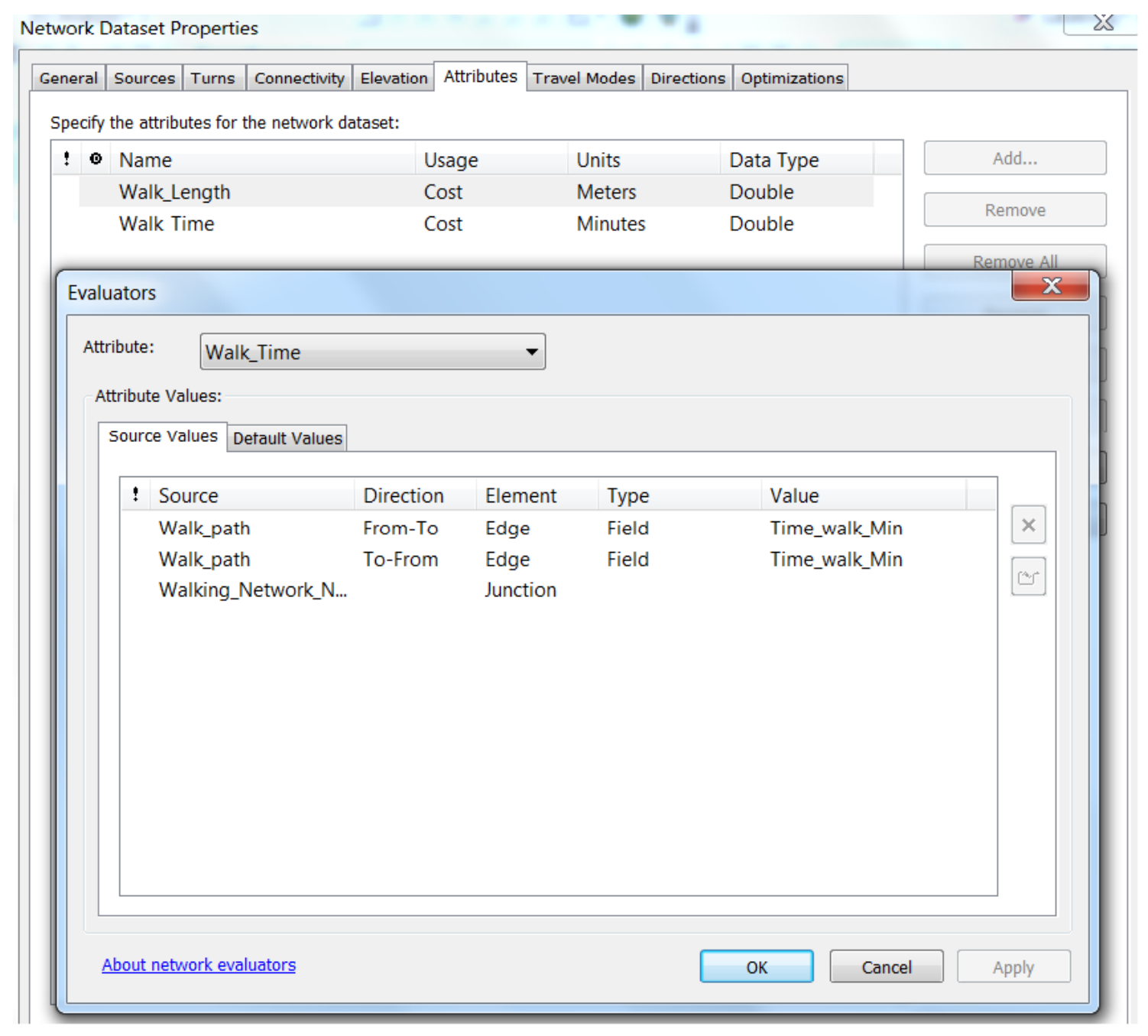

Figure 5-8: Defining the Network Dataset Attributes 


\subsection{New Urbanism and Geodesign Application}

The New Urbanism concept was used to improve the study area accessibility by providing walkable streets, as well as determining new location for new services. Based on New Urbanism principles, specific walking distance was defined for each type of service. The service area analyses were performed with these estimated distances. After implementing these analyses, optimal locations for each service were collected. Table 5-1 illustrates the estimated distances for each type of service. Two scenarios were designed based on those analysis results. A geodesign technique was used to evaluate accessibility and feasibility of the study area, and the two designed scenarios. The accessibility of the study area and the two scenarios were evaluated through performing service area analysis.

Table 5-1: The Estimated Walking Distances for Each Service Area

\begin{tabular}{|l|l|}
\hline Services Type & Estimated Distances \\
\hline Schools & 400 meters \\
\hline Hospitals & 1,500 meters \\
\hline Groceries & 400 meters \\
\hline Mosques & 400 meters \\
\hline Parks & 400 meters \\
\hline Malls & 1,500 meters \\
\hline
\end{tabular}




\subsection{Summary}

This chapter discussed the implementation methods that were used to reach the final outcomes of the project. These implementation methods included: data creation and preparation, 3D modeling, service area analysis, and the application of New Urbanism and Geodesign. All of these methods were performed using ArcGIS for Desktop except for the 3D model, which was built via ArcGIS Pro. 


\section{Chapter 6 - Results and Analysis}

In this chapter, the overall results of the project and its benefits to the client can benefit from them are discussed. All the results of the project were created and generated via ArcGIS for Desktop, ArcGIS Pro, and SketchUp software. This chapter consisted of four sections: 3D modeling of the study area, services accessibility of the study area, two designed scenarios, and a summary.

\subsection{D Modeling of the Study Area}

a $3 \mathrm{D}$ modeling is one of the main project's objectives that was required by the client. This output helps provide a better understanding of complex urban planning regulations and a better visualization for the current condition of the existed development or plan. In other words, 3D model provides a complete picture of the existing development, which helps to obtain better results of the current and future urban design projects. Figure 6-1 shows the 3D modeling of the study area. Also, three well-known building facades were designed in order to represent more realistic simulation of the study area include: the biggest mall, the tallest hotel, and a well-known mosque. Figure 6-2 presents the facade design of these three buildings. 


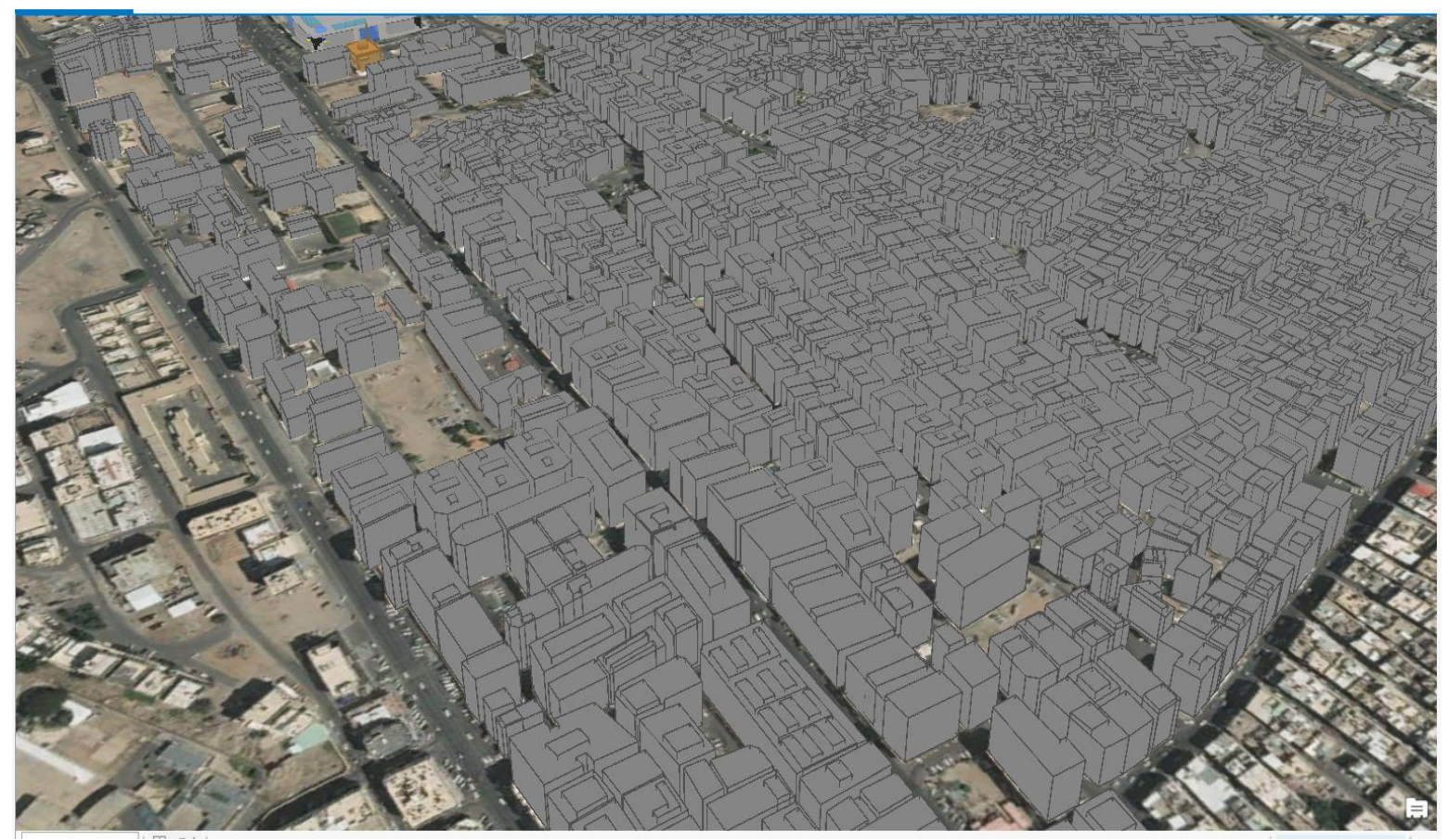

Figure 6-1: 3D Example View of the Study Area

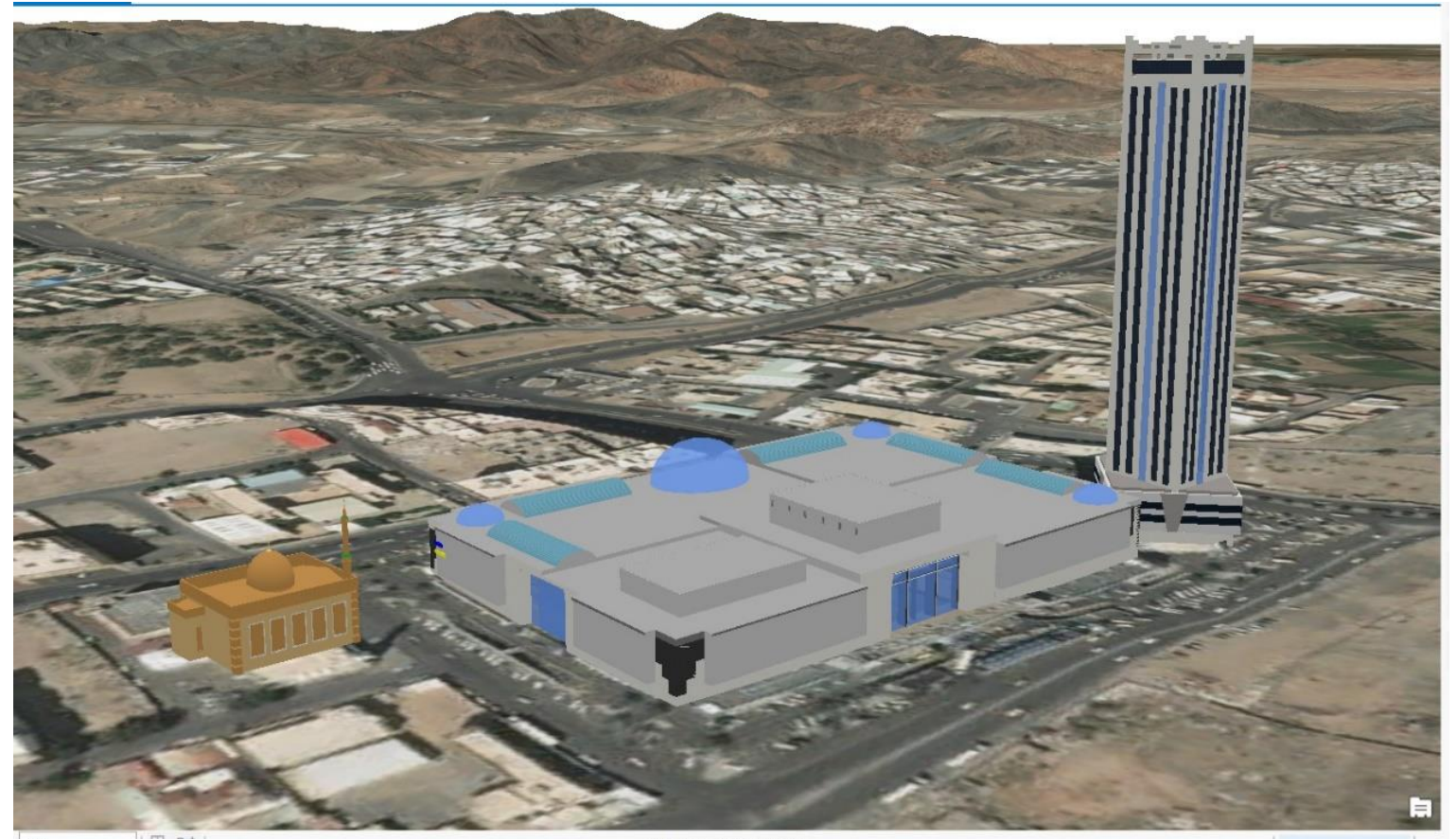

Figure 6-2: The Facade design of the Three Buildings 


\subsection{Services Accessibility of the Study Area}

Analysis of the study area's service accessibility is an important objective of the project. Calculating service areas for the current study area services provides information about which areas are being served or unserved, and whether all the services are accessible or not to residents. The ArcGIS Network Analyst extension was used for this part of the project to calculate and determine the served area of each service. A set of service accessibility maps were generated for the study area in order to identify served and unserved areas for each service. The following figures (6-3 - 6-9) illustrate the service area accessibility for each type of service including: schools, parks, mosques, groceries, hospitals, and malls. Through the results of these analyses, the malls and the health facilities were available and accessible within the whole study area. The north part of the study area does not have the following facilities such as the groceries and schools. Moreover, most of the study area lacks access to from parks and entrainment facilities These results were considered for designing the scenarios. 


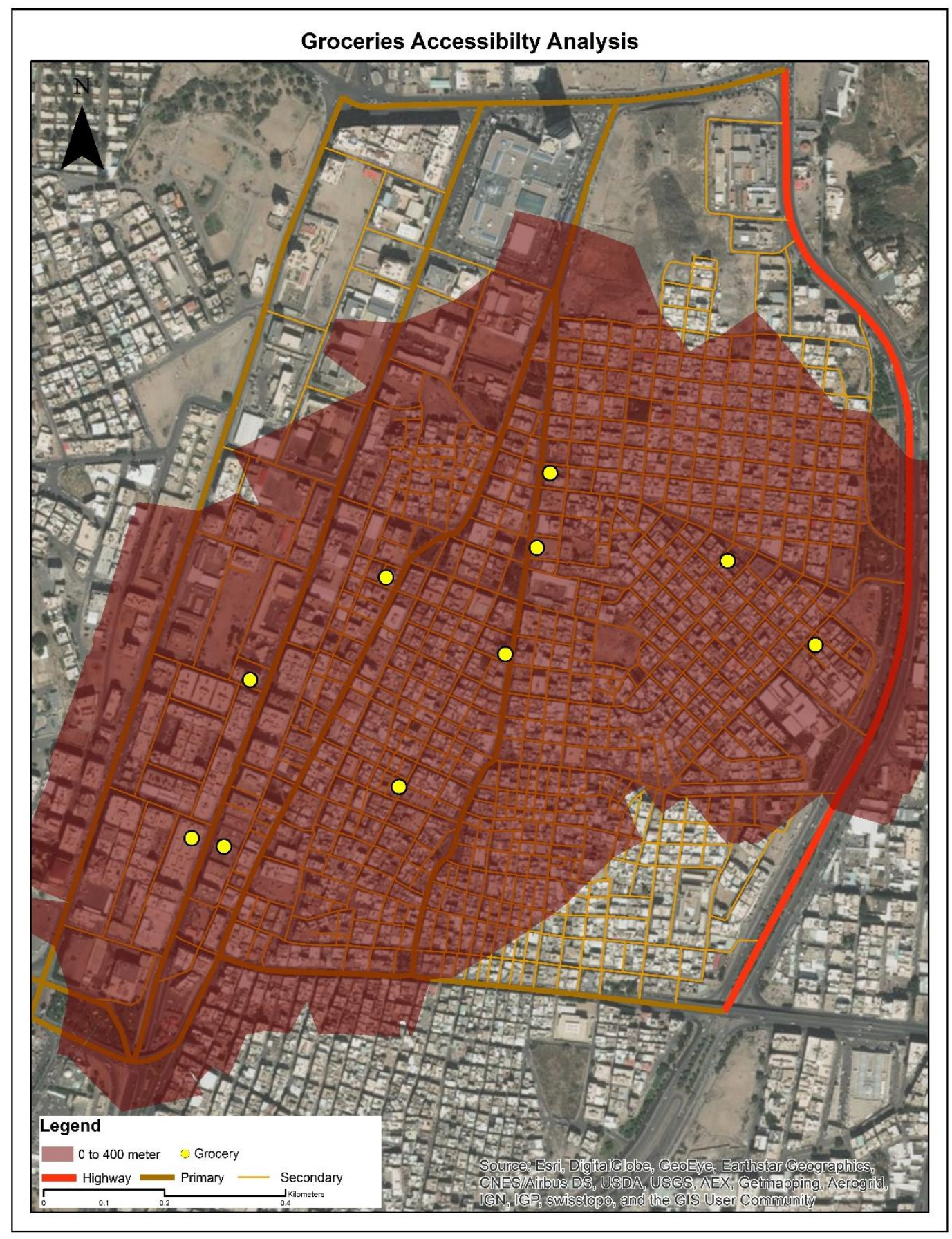

Figure 6-3: Groceries Accessibility Analysis within 400 Meter 


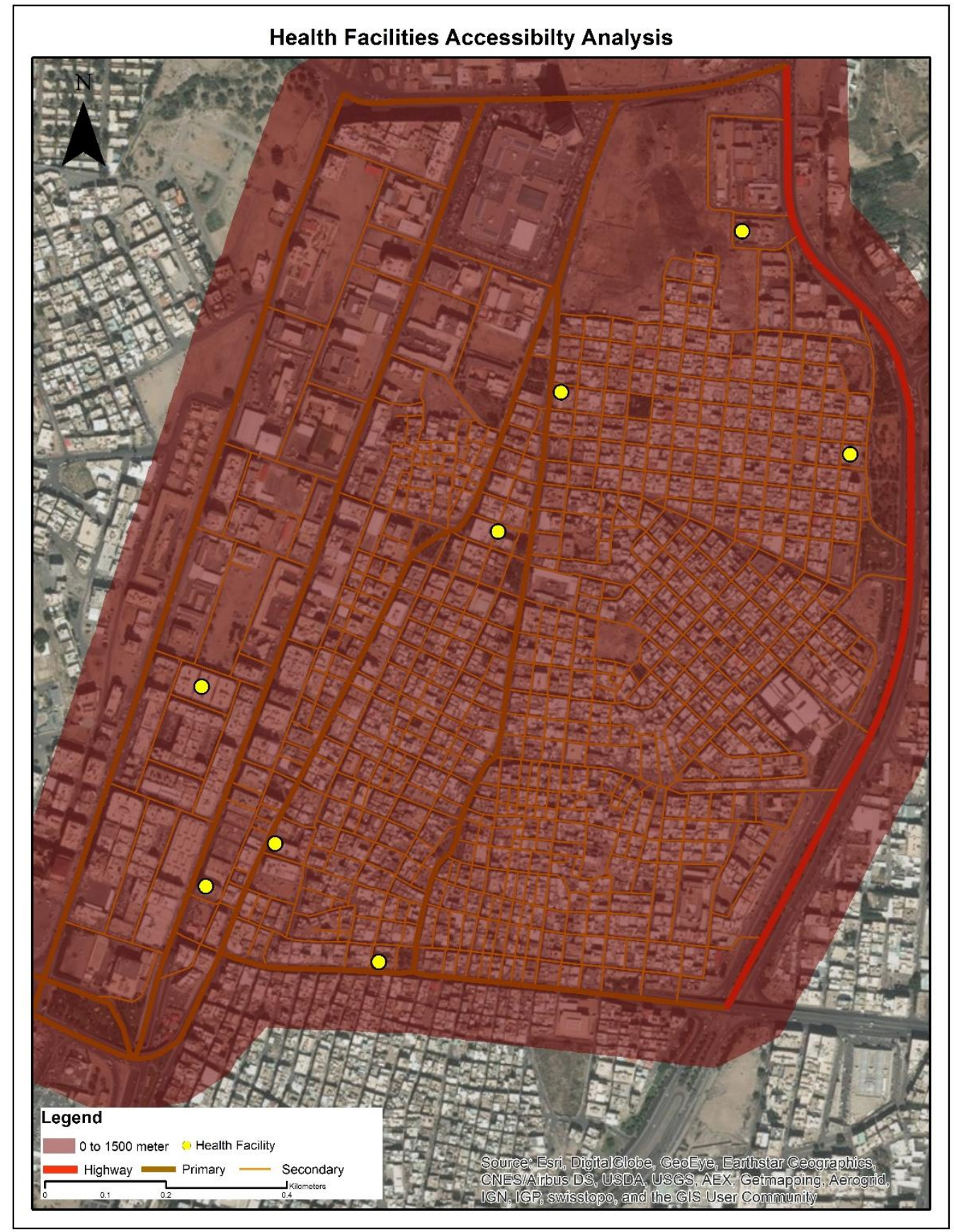

Figure 6-4: Health Facilities Accessibility Analysis within 1.5 Kilometers 


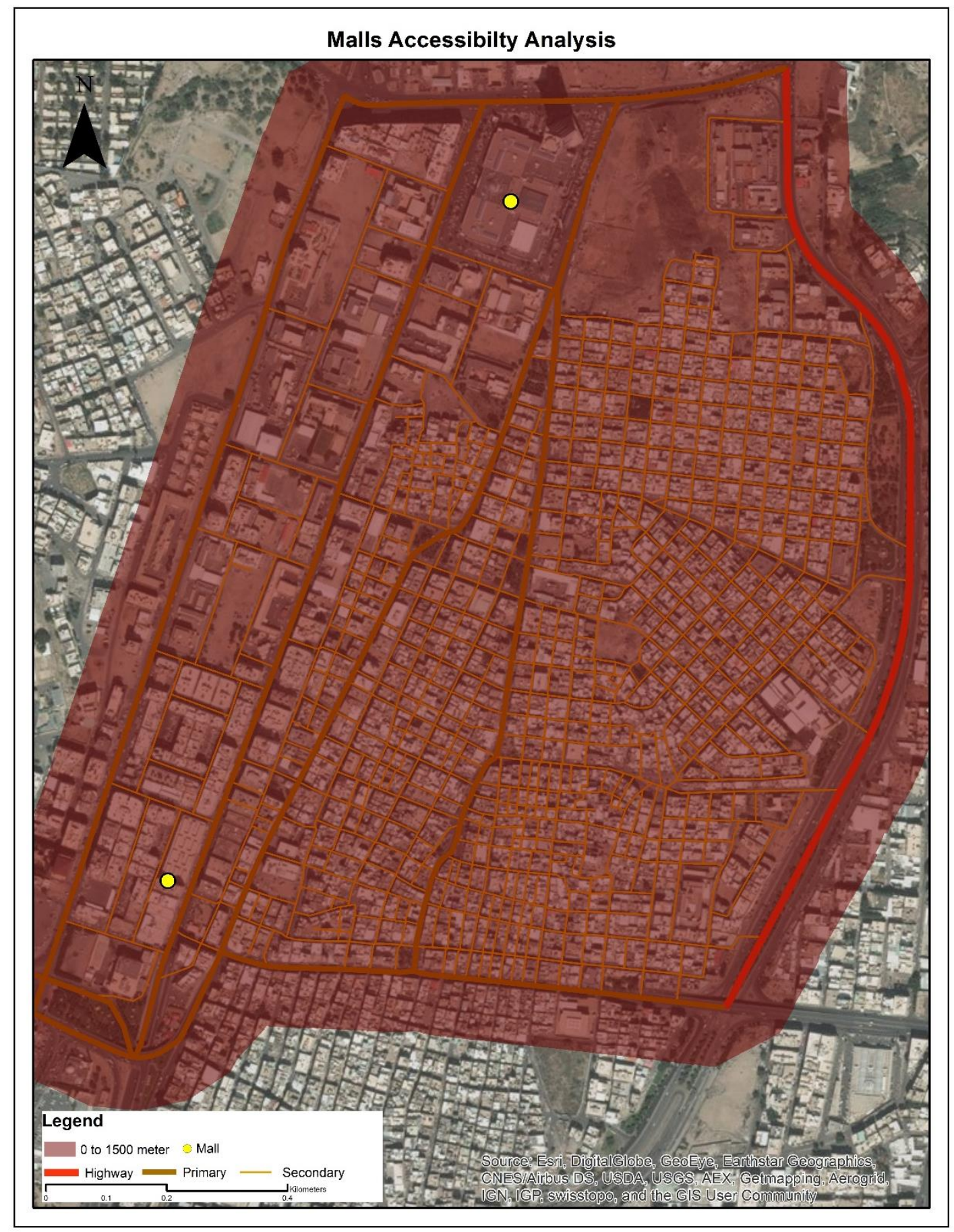

Figure 6-5: Malls Accessibility Analysis within 1.5 Kilometers 


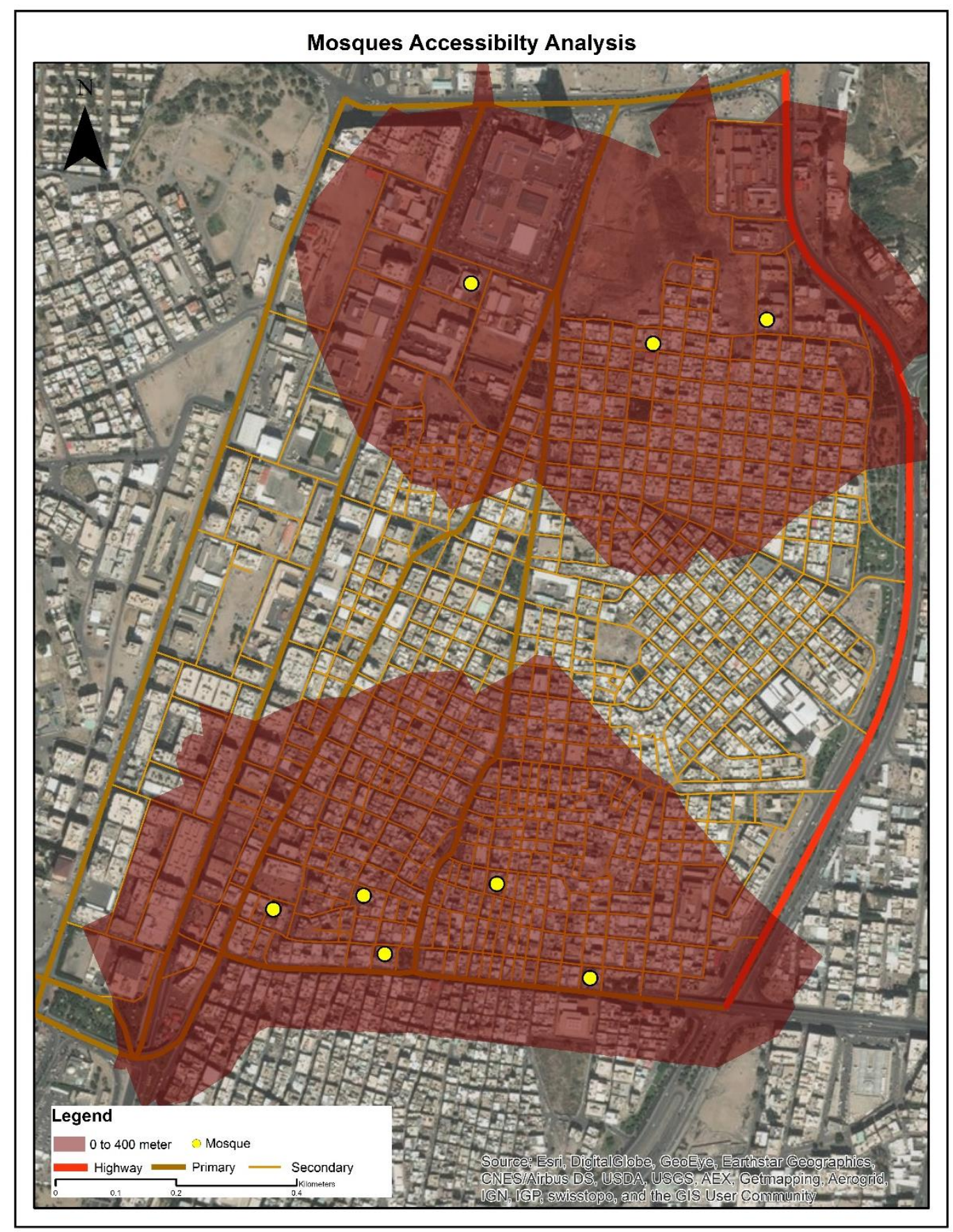

Figure 6-6: Mosques Accessibility Analysis within 400 Meter 


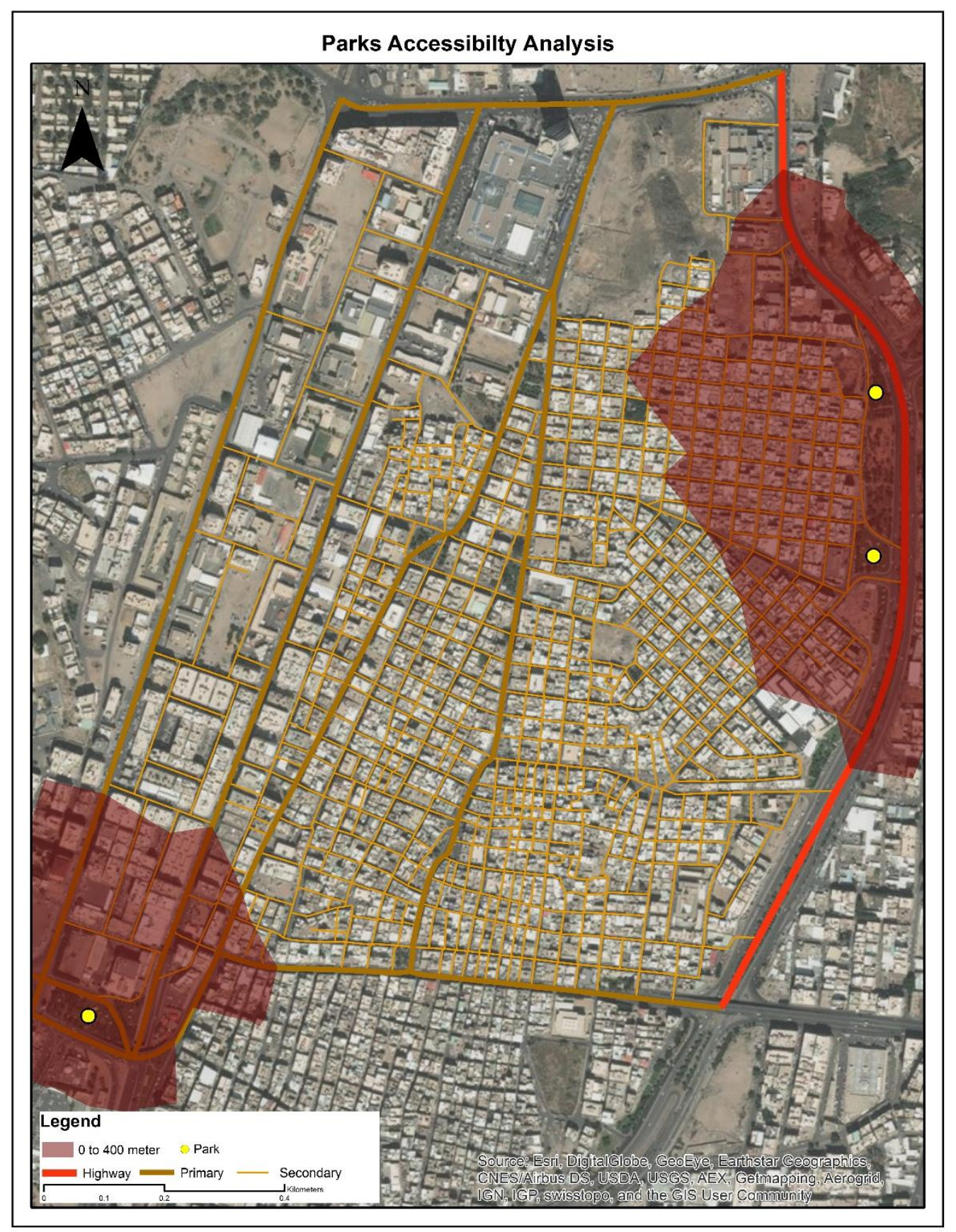

Figure 6-7: Parks Accessibility Analysis within 400 Meter 


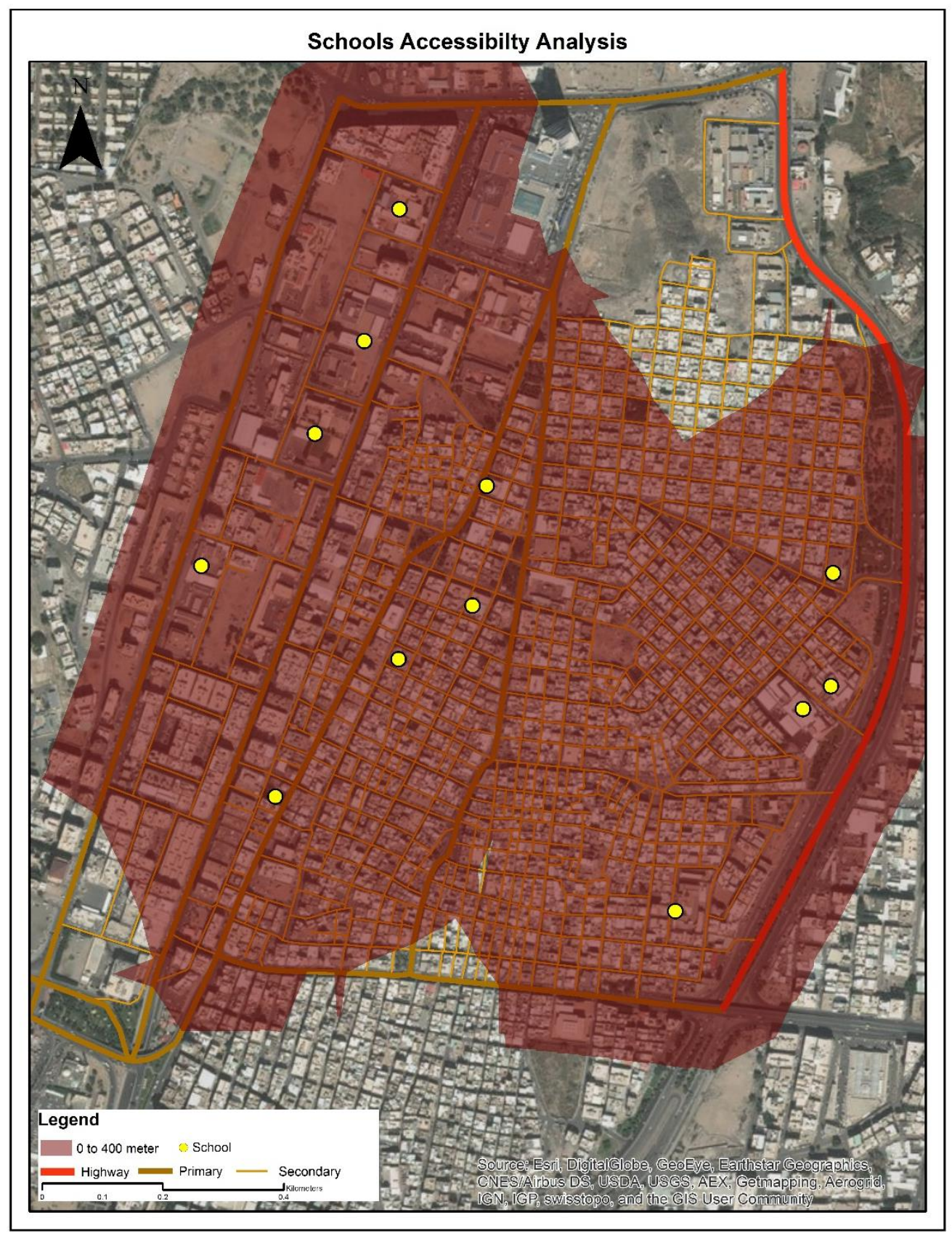

Figure 6-8: Schools Accessibility Analysis within 400 Meter 


\subsection{Two Designed Scenarios}

The goal of designing the scenarios is to help the client provide a mixed-use and healthy neighborhood that has walkable and reasonable access to services. To achieve this goal, several principles from geodesign, New Urbansim, and the client's ideas were involved. First, providing services within 4 to 6-minute (400 meter) walk was considered. Then, creating accessible public facilities and green spaces for citizens' leisure and entertainment was involved, which was required by the client. Also, the client wanted to address proposed development after the demolishment of the old part of the study area (figure 6-9), so creating and upgrading facilities; parks, and infrastructure were taken into consideration while designing the scenarios. Also, all the suggested locations for new services in both scenarios were chosen based on the service area accessibility analysis. 


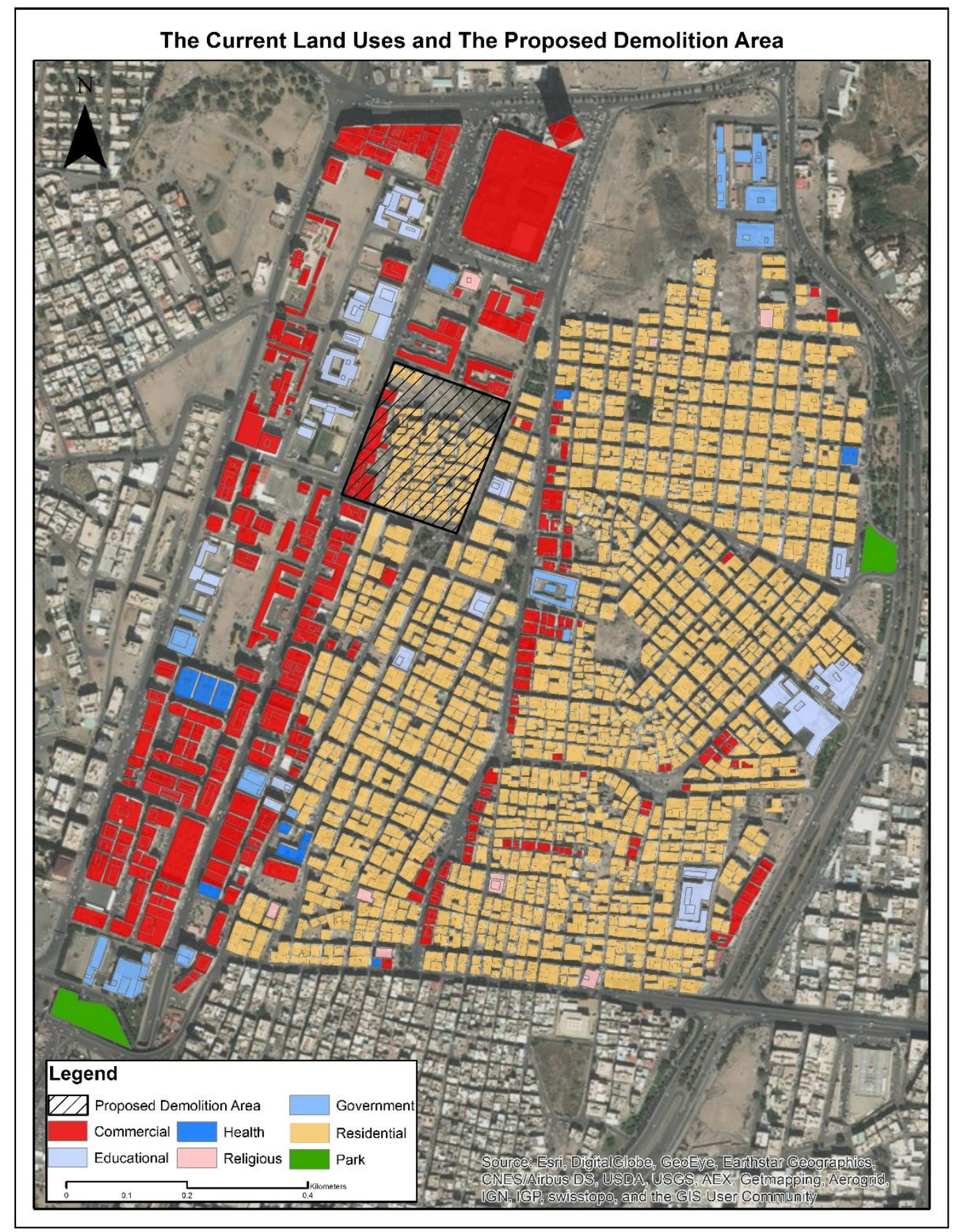

Figure 6-9: The Current Land Uses and The Proposed Demolition Area 
The first scenario of the study area supports the client's desire to demolish the area specified in the figure 6-10. Based on the accessibility analyses, most of this demolished area was replaced with a new park that contains sport facilities, and the rest of this area was used for commercial purposes. This scenario required upgrading and developing the exciting parks. Suitable locations for a new school and two mosques were chosen. Moreover, several commercial areas were determined in order to increase the number of needed services such as groceries, gathering places, and a gas station. Also, a mixed density residential area was provided in this scenario. To sum up, this scenario considered all of the client's needs and opinions in the proposed development plan for the study area. Figure 6-11 shows the first designed scenario for the study with the current land. 


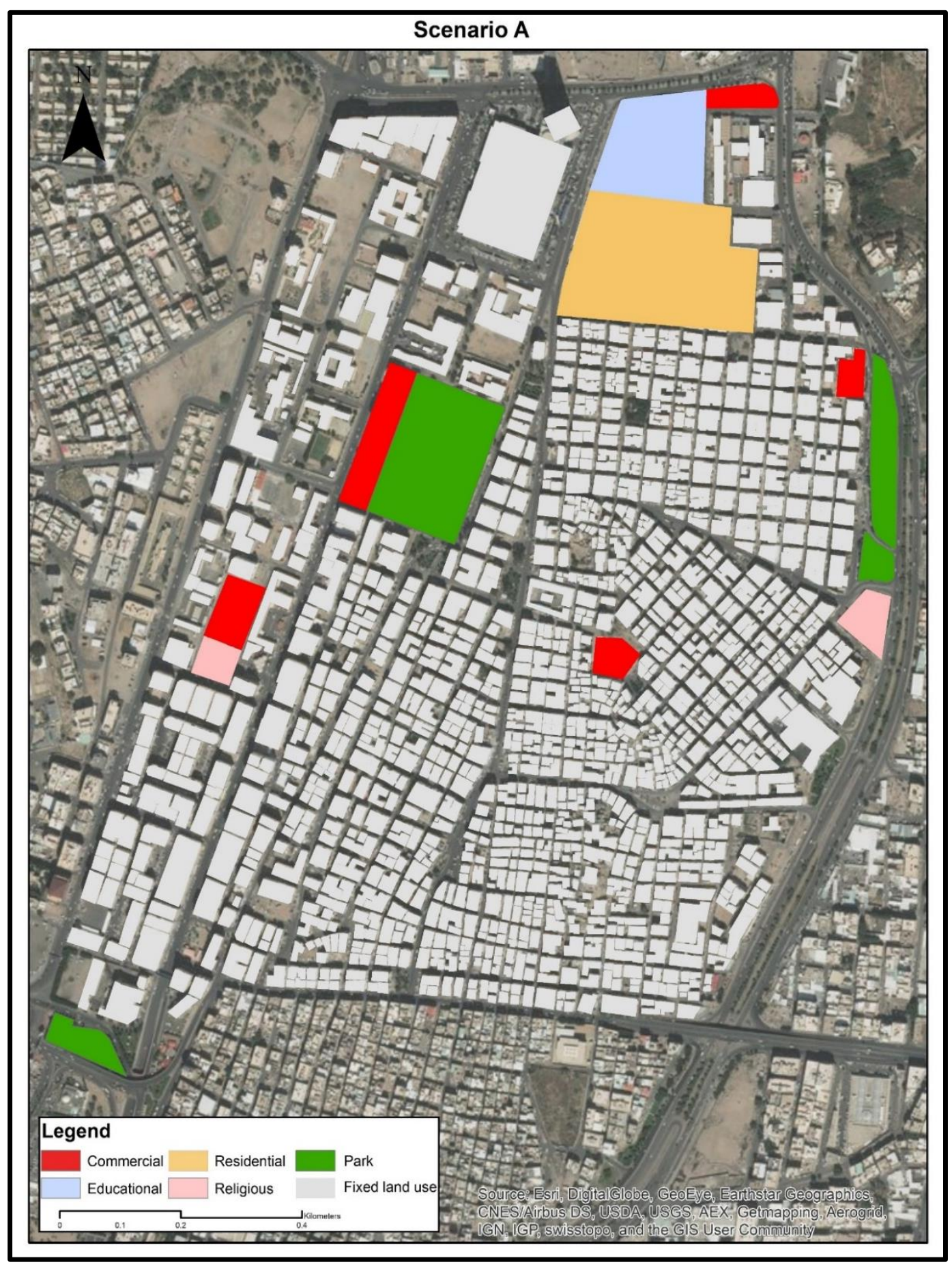

Figure 6-10: The First Scenario for the Study Area 
The second scenario of the project's study area was also designed and created based on the results of the service area accessibility analysis while considering all the previous principles of geodesign, New Urbanism, and the client. This scenario supported most of the client's needs and requests, but it offered an alternative to demolishing the old part of the study area. This old area contains buildings that were built decades ago and they can be preserved and used as a historical area of the city. Also, if this area was upgraded, it would promote cultural tourism in the city and attract new local businesses because of its old structures. This scenario provided a more mixed-density residential area, new parks, a new mosque, and a commercial area that could include a gas station and a grocery in order to obtain the needed services for the study area. Figure 6-11 shows the second designed scenario for the study area. 


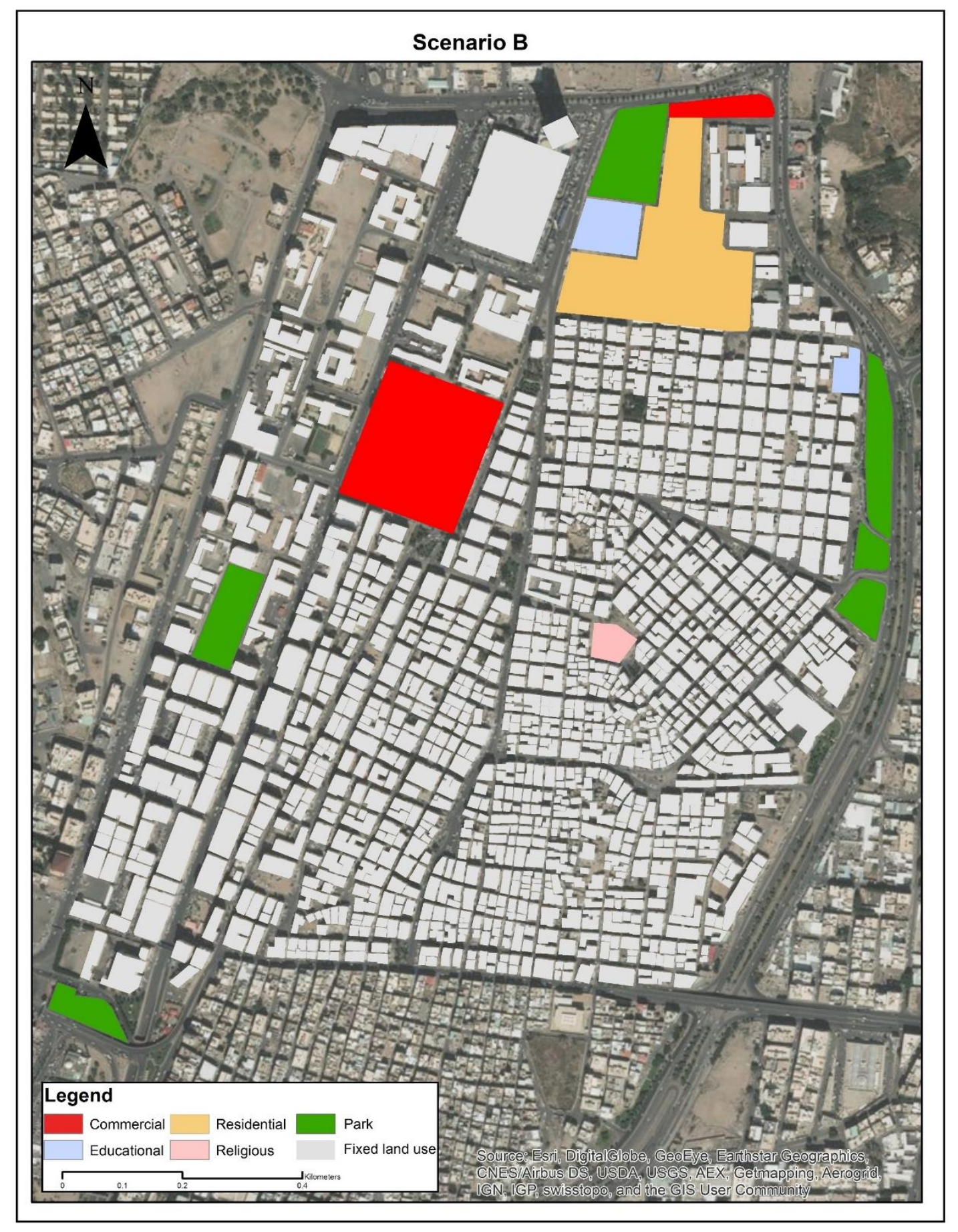

Figure 6-11: The Second Scenario for the Study Area 
Both scenarios were designed to obtain a livable and sustainable community for the study area by increasing business opportunities, providing a mix of land uses, and making all the services accessible within a walkable distance. Table 6-1 evaluates both scenarios based on three factors include: accessibility, business opportunities, and mixeduse. Also, Table 6-2 shows a comparison about how much land area is being allocated for specific land uses in both scenarios.

\section{Table 6-1: Evaluation of Both Scenarios}

\begin{tabular}{|l|l|l|l|}
\cline { 2 - 4 } \multicolumn{1}{c|}{} & \multicolumn{1}{c|}{ Accessibility } & Business opportunities & \multicolumn{1}{c|}{ mixed-use } \\
\hline Scenario & $\begin{array}{l}\text { - Both scenarios } \\
\text { provided services } \\
\text { Aithin a walkable } \\
\text { distance }\end{array}$ & $\begin{array}{l}\text {-Less commercial areas } \\
\text { were provided such as } \\
\text { groceries, gas station } \\
\text {-Business park was } \\
\text { provided in the middle } \\
\text { of the study area }\end{array}$ & $\begin{array}{l}\text {-A mix of residential, } \\
\text { commercial, } \\
\text { entertainment, and } \\
\text { religious areas on the } \\
\text { site } \\
\text {-Public sports facility }\end{array}$ \\
\cline { 3 - 5 } Scenario & $\begin{array}{l}\text {-Both scenarios } \\
\text { contain different } \\
\text { services close to each } \\
\text { other }\end{array}$ & $\begin{array}{l}\text {-More commercial } \\
\text { areas } \\
\text { B A historical area was } \\
\text { kept }\end{array}$ & $\begin{array}{l}\text {-A mix of residential, } \\
\text { commercial, historical, } \\
\text { religious, and green } \\
\text { areas on the site }\end{array}$ \\
\hline
\end{tabular}

Table 6-2: Comparison The Added Land-uses of Both Scenarios:

\begin{tabular}{|l|l|l|}
\hline Land use & $\begin{array}{l}\text { Scenario A } \\
\left(\mathrm{m}^{2}\right)\end{array}$ & $\begin{array}{l}\text { Scenario B } \\
\left(\mathrm{m}^{2}\right)\end{array}$ \\
\hline Residential & 50,323 & 48,553 \\
\hline Commercial & 23,988 & 26,518 \\
\hline Religious & 8,687 & 3,686 \\
\hline Green area & 32,757 & 67,479 \\
\hline Educational & 26,998 & 8,740 \\
\hline
\end{tabular}




\subsection{Summary}

This chapter described the results of the project. The first section covered the 3D modeling of the study area. The second section explained the services accessibility of the study area and contained six maps. The third section provided optimal designed scenarios for the study area based on the services accessibility analysis, and the principles of geodesign, New Urbanism, and the client. 



\section{Chapter 7 - Conclusions and Future Work}

The objectives of this project were to create a 3D model for the study area, perform an accessibility analysis for most of services of the study area, and design two suggested scenarios. This chapter explains the project conclusion in section 7.1. Also, a few suggestions for improving the project in the future are provided in section 7.2.

\subsection{Conclusion}

All of these objectives were implemented via ArcGIS for Desktop and ArcGIS Pro. The 3D model was created to provide an actual simulation for the study area. This simulation is currently helping the client understand the study area clearly in order to obtain better design results of the current and future proposed development. The services accessibility analyses were performed with ArcGIS Network Analyst in order to calculate the service area of most services within the study area. These analyses would help the client to determine the access of services to residents, and whether the study area needs more services. Also, the results of those analyses would help the client evaluate proposed development plans for the study area. The two suggested scenarios of the study were designed based the results of the service area analysis. While designing these scenarios, a few common goals were made a priority in order to increase the level of livability as well as reduce the dependency on automobiles. Providing more amenities, activities, and services within walkable distances in the study area are in both scenarios.

\subsection{Future Work}

Several different recommendations and suggestions can be applied to this project in order to improve it. These include publishing 3D web scenes, adding more data, and 
conducting 3D analysis. A 3D web scene of the study area is strongly recommended in terms of improvement. By using Esri software such as ArcGIS Pro or CityEngine, the 3D web scene can be published and shared with the client's organization, citizens, and other people of interest. In turn, they would be able to visualize, communicate, and add comments to each feature. In other words, the $3 \mathrm{D}$ web scene could be used as a collective platform for citizens, urban designers and planners, and decision makers.

Another suggestion that could improve the two scenarios of this project would be to add other types of data such as socio-economic, environmental, and crime data. Analyzing the socio-economic data would help the client to understand the effects of economic activities on the study area, and the price of land in it, as well as the kind of people are living in or around the study area. Also, by analyzing crime data and environmental data such as flood areas, noise areas, soil types, and environmental hazard areas it would be possible to design more efficient and feasible scenarios for the study area.

A final suggestion for developing the project further is to use the created 3D model of the study area for performing 3D analysis. Through ArcGIS 3D Analyst, the client could implement several types of 3D analysis. For example, the shadow cast and the impact of proposed buildings on the existing views could be determined, and the contour and the slope of the study area could be analyzed as well. 


\section{Works Cited}

Congress for the New Urbanism. (2016). What is New Urbanism? Retrieved from https://www.cnu.org/resources/what-new-urbanism

Davidson, K. (2006). Designing a walkable suburban landscape: New urbanism and light rail as methodologies.

Esri. (2014, December). 3D Urban Mapping: From Pretty Pictures to 3D GIS. Retrieved from https://www.esri.com/library/whitepapers/pdfs/3d-urban-mapping.

Esri. (2016). 3D. Retrieved from http://www.esri.com/products/arcgis-capabilities/3d-gis

Esri. (2016). ArcGIS for Network Analyst.

http://www.esri.com/software/arcgis/extensions/networkanalyst

Esri. (2016). GIS Solutions for Urban and Regional Planning: Designing and Mapping the Future of Your Community with GIS. Retrieved from http://www.esri.com/library/brochures/pdfs/gis-sols-for-urban-planning

Esri. (2016). Network Elements. Retrieved from http://desktop.arcgis.com/en/arcmap/latest/extensions/network-analyst/networkelements.htm

Kim, S., Lee, J., and Randy, A. (2008). Informing the Debate Informing the Debate New Urbanism in Michigan. Retrieved from http://ippsr.msu.edu/Publications/ARNewUrbanism.pdf

Kumar, P., and Kumar, D. Network Analysis using GIS Techniques: A Case of Chandigarh City.

New Urbanism. (2016). Creating Livable Sustainable Communities. Retrieved from http://www.newurbanism.org/newurbanism.html

Steinitz, C. (1990). Steinitz's Framework. Retrieved from http://www.spatial.redlands.edu/sds/ontology/?n=SDSSWorkflow:LandscapeCha ngeModel

Steinitz, C. (2012). A Framework For Geodesign: Changing Geography By Design.

The Saudi Network. (2016). Taif City Profile. Retrieved From http://www.thesaudi.net/saudi-arabia/taif/Taif\%20-\%20Saudi\%20Arabia.htm 
Zhang, H., Li, Y., Liu, B., \& Liu, C. (2014). The Application of GIS 3D Modeling and Analysis Technology in Real Estate Mass Appraisal-Taking landscape and sunlight factors as the example. The International Archives of Photogrammetry, Remote Sensing and Spatial Information Sciences, 40(4), 363 
